\title{
Working
}

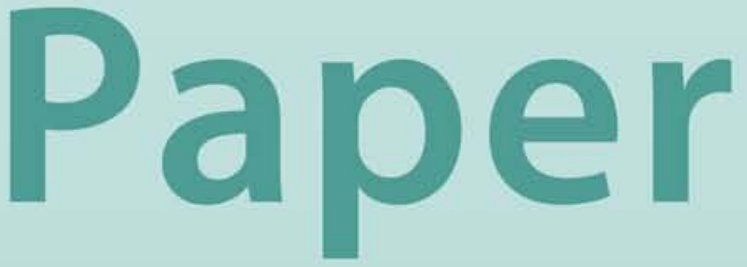


New Shocks, Exchange Rates and Equity Prices

\author{
Akito Matsumoto, Pietro Cova, \\ Massimiliano Pisani, and Alessandro Rebucci
}




\title{
IMF Working Paper
}

Research

Department

\section{New Shocks, Exchange Rates and Equity Prices ${ }^{1}$}

\section{Prepared by Akito Matsumoto, Pietro Cova, Massimiliano Pisani and Alessandro Rebucci}

\author{
Authorized for distribution by Stijn Claessens
}

December 2008

\begin{abstract}
This Working Paper should not be reported as representing the views of the IMF. The views expressed in this Working Paper are those of the author(s) and do not necessarily represent those of the IMF or IMF policy. Working Papers describe research in progress by the author(s) and are published to elicit comments and to further debate.
\end{abstract}

We study exchange rate and equity price dynamics, in general equilibrium, in the presence of news shocks about future productivity and monetary policy. We identify a condition under which these asset prices become more volatile without affecting the volatility of the underlying processes - a positive correlation between news and current shocks. This condition also explains why persistent underlying processes generate volatile asset prices. In addition, we show that the correlation between exchange rate and equity returns depends critically on the currency denomination of the equity return and the monetary policy reaction to productivity shocks. The model we set up does well at matching second moments of exchange rate and equity returns for major floating currencies.

JEL Classification Numbers:E32; F30; F40; G11.

Keywords: News Shocks, Exchange Rates, Equity Prices, Productivity, Monetary Policy, Persistence

Author's E-Mail Address: amatsumoto@imf.org; pietro.cova@bancaditalia.it; massimiliano.pisani@bancaditalia.it; alessandror@iadb.org

\footnotetext{
${ }^{1}$ We thank Charles Engel and participants at the ESRC-IMF conference on intranational macro-finance, especially our discussant, Martin Bodenstein, for comments and suggestions. We are grateful to Patrick Hettinger for research assistance. The views expressed in this paper are those of the author and should not be attributed to the Bank of Italy, the International Monetary Fund, their Executive Board, or their management. All errors are of the authors.
} 


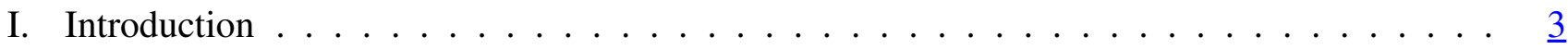

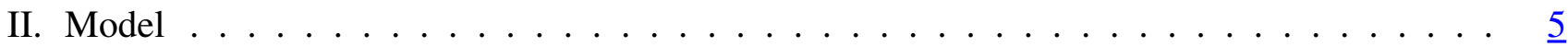

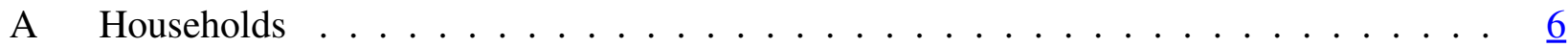

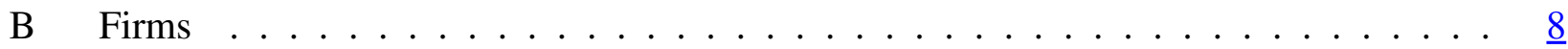

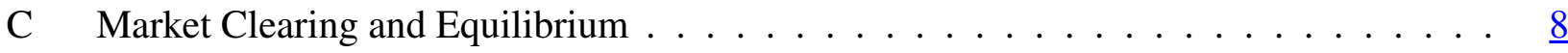

D Stochastic Processes and Information Assumptions $\ldots \ldots \ldots \ldots$

III. Solution and Properties . . . . . . . . . . . . . . . . . . . . 10

A News Shock and Exchange Rate Predictability . . . . . . . . . . . . . . . 11

B Exchange Rate Volatility . . . . . . . . . . . . . . . . . 12

C Equity Return Volatility . . . . . . . . . . . . . . . . . . . . . . . . . 14

D Exchange Rate and Equity Price Comovement . . . . . . . . . . . . . . . 19

IV. Quantitative Analysis . . . . . . . . . . . . . . . . . . 20

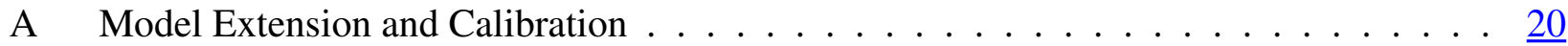

B Impulse Responses . . . . . . . . . . . . . . . . . . . . . . . . . 22

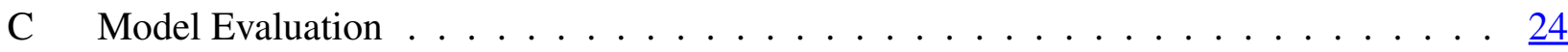

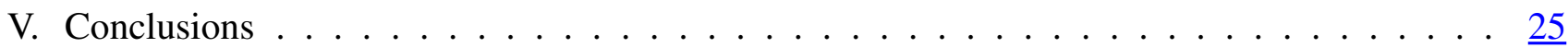

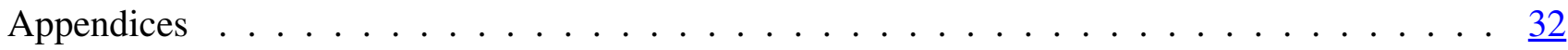

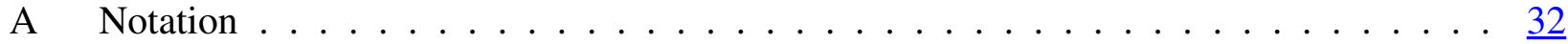

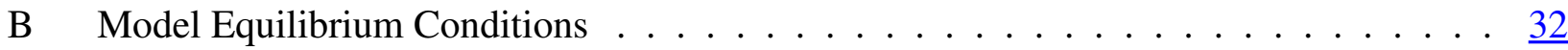

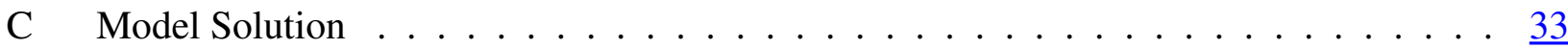

D Extended Model Equilibrium Conditions . . . . . . . . . . . . .

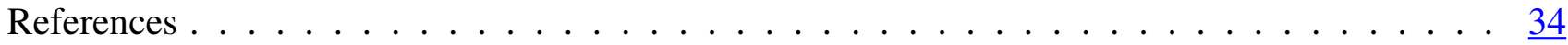

Tables

1 Model Evaluation . . . . . . . . . . . . . . . . . . . . . 27

2 Volatility and Comovement of Exchange Rates and Equity Returns . . . . . . . . . 28

Figures

1 Impulse Response to Current and News Shocks (No Smoothing) . . . . . . . . . . . . 29

2 Impulse Response to Current and News Shocks (Interest Rate Smoothing) . . . . . . . . . $\underline{30}$

3 Impulse Response of Home to Home Current and News Shocks (Smoothing) . . . . . . . 31 


\section{INTRODUCTION}

Information about the future plays an important role in asset price dynamics, regardless of whether agents have rational expectations, noisy expectations, or have accurate news about the future. And a growing recent literature studies the importance of news shocks for asset price dynamics. Engel and West (2005), in particular, show that exchange rates are hard to predict because they are discounted sums of expected future fundamentals, which follow I(1) processes. In addition, Engel and West (2005) show that exchange rates can predict macroeconomic fundamentals as present value models would. Engel, Mark, and West (2006) present empirical evidence showing that exchange rates indeed incorporate news about future macroeconomic fundamentals. Beaudry and Portier (2006) investigate the role of information about future productivity on equity price and show that news shocks about productivity can explain a significant fraction of equity price volatility empirically. ${ }^{2}$

Equity prices and exchange rates share many puzzling empirical features, including excess volatility with respect to their fundamentals. In addition, over the past several years we have witnessed a spectacular increase in cross-boarder equity flows whose returns are affected by both equity returns in local currency and exchange rate returns. Despite sharing common empirical features, surprisingly little attention has been devoted to the analysis of these commonalities and the comovement between these two asset prices. ${ }^{3}$

In this paper, we study the role of news about future productivity and monetary policy for equity price and exchange rate dynamics in a standard dynamic stochastic general equilibrium (DSGE) open economy model. ${ }^{4}$ We focus on volatility and comovement under alternative information assumptions and monetary policy reactions to productivity shocks. ${ }^{5}$

While allowing for news shocks to productivity is not controversial, considering monetary policy news is more novel. We think about monetary policy news as the by-product of an active communication strategy aimed at guiding expectations about the future course of monetary policy, as we observe it in practice. ${ }^{6}$ In this paper, we do not provide the rationale for an active monetary policy communication strategy, but we study its effect on exchange rate and equity price dynamics. In practice, policy news shocks are important as evidenced by the federal fund rate futures moving, following monetary policy meetings and the release of other communications, without changes in the federal fund target rate.

\footnotetext{
${ }^{2}$ The role of news shocks about productivity in the business cycle is studied by Jaimovich and Rebelo (2006, 2007) among others.

${ }^{3}$ Some notable exceptions are Hau and Rey (2004, 2006), Andersen, Bollerslev, Diebold, and Vega (2007), and Brandt, Cochrane, and Santa-Clara (2006).

${ }^{4}$ In this paper, 'news' is strictly defined as new information about future fundamentals. Most of the literature define 'news' as new contemporaneous information, i.e., a surprise to current variables. We use "current shocks" to label surprises to current variables.

${ }^{5}$ Devereux and Engel $(2006,2007)$ study the role of news about future productivity in determining optimal monetary policy. We ask a related but different question: namely, what is the impact of monetary policy on exchange rate and equity price dynamics in the presence of news shocks.

${ }^{6}$ See Woodford (2008) and Blinder et al (forthcoming) for example.
} 
The model we set up is an extension of that of Devereux and Engel $(2006,2007)$. This is a relatively simple, monetary, open economy model with production, sticky prices in local currency, and complete markets. Currency and equity composition of the country portfolios do not affect real allocations in the model given the complete market assumption. Nonetheless, in this setting, we can price equity claims and study the impact of macroeconomic fundamentals on equity prices using the pricing kernel derived from the complete market assumption. The model is simple enough to yield closed form solutions for key moments. A more realistic version is solved numerically and its implications are contrasted to the data for the foreign exchange and equity markets of the United States, Japan, Germany, and the UK.

The paper's main contribution is twofold. First, we identify a condition-a positive correlation between current and news shocks - on the information content of the news shocks in our model that generates higher volatility of exchange rates and equity prices. West (1988) shows that, in general, more accurate information about the future reduces volatility of asset prices. We show that when news shocks are positively correlated with current shocks, asset prices become more volatile, for a given volatility of the underlying stochastic processes. For example, if the underlying dividend process is such that unexpected higher (lower) dividend growth today tends to be accompanied by news about higher (lower) future dividend growth, then the equity price becomes more volatile than in the case in which news is not correlated with the current surprise. This mechanism thus explains some of the excess volatility in asset prices relative to the fundamentals that we see in the data.

The intuition for this result is that asset prices are forward looking and respond to information about the future evolution, in addition to current values, of their fundamentals. Specifically, asset prices respond to both current shocks (today's surprise) and news shocks (today's new information about future), while fundamentals evolve according to today's current shocks and yesterday's news shocks. But yesterday's news shocks can potentially offset today's surprises, while today's surprises and today's news shocks are likely to move in the same direction if positively correlated. In other words, if current and news shocks are positively correlated, news about future fundamentals have an information content similar to today's surprise, and asset prices can move more in the same direction than the fundamentals.

This condition also provides an economic interpretation of why persistent processes generate volatile asset prices. The positive correlation between current and news shocks introduces a link between today's and tomorrow's value of the fundamental, analogous to the one introduced by a standard, persistent underlying stochastic process. Indeed, fundamental variables, such as productivity, interest rates, and dividends, tend to be highly serially correlated from an econometrician's point of view, and DSGE models incorporating higher persistence are more successful in generating higher asset price volatility.

Second, we show that the comovement between exchange rate and equity return differentials hinges on the currency denomination of the equity returns and monetary policy. News shocks do not play a crucial role for this comovement because they affect equity prices and exchange rates in a similar way. More specifically, our analysis shows that the correlation between the equity return differential measured in investor currency and the exchange rate return depends crucially on the monetary policy reaction to productivity. If there is no systematic monetary policy, or if monetary policy does not respond to the output gap, equity return differentials measured in investor currency are independent of the exchange rate and are affected only by current and news shocks to productivity. If there is a monetary policy response to the output gap, the model generates a positive, counterfactual correlation between equity return differentials measured in investor currency and exchange rates. The model, 
however, can also generate a data-consistent negative correlation between equity return differentials in investor currency and exchange rate returns assuming a small negative monetary response to the output gap - an assumption that may be questionable but is plausible in our model (in which the output gap is defined relative to flexible price output) as long as this coefficient is small enough to guarantee the uniqueness of the equilibrium.

Consistent with the data, our model also generates a positive correlation between equity return differentials measured in firm local currency and exchange rate returns, even under the assumption of complete asset markets, for a reasonable range of parameter values and monetary policy specifications. In addition, we show that if productivity shocks are more volatile than monetary shocks, then equity returns tend to be more volatile than exchange rate returns as in the data. We therefore conjecture that, in the data, the small size of the correlation between equity return differentials in local currency and exchange rate returns is due to the higher volatility of current and news shocks to productivity, which affect mostly equities, relative to monetary shocks, which affect both exchange rates and equity returns with a similar intensity. Notice that the model of Hau and Rey (2006) also generates a positive correlation between exchange rate changes and relative equity returns in local currency assuming incomplete asset markets. Their model, however, predicts a counterfactual perfect correlation between equity and exchange rate returns, while our model predicts correctly not only the sign but also the magnitude of this correlation. ${ }^{7}$

The paper also shows analytically the mechanism through which exchange rates and equity prices take news about the future into account. While it is often given for granted that policy announcements affect asset prices, we illustrate the transmission mechanism rigorously, and also show that the impact of an "announcement" is qualitatively different from the impact of an unanticipated "actual" policy change. Interestingly, this suggests that event studies of the effect of monetary policy on equity prices may be biased if they focus only on actual unanticipated policy changes. ${ }^{8}$

The rest of the paper is organized as follows. Section 2 sets up the model. Section 3 reports and discusses the main analytical results on equity price and exchange rate volatility and their comovement. Section 4 extends the model to staggered pricing and rule-based interest rate setting, and evaluates it against the data. Section 5 concludes. The full solution of the model, as well as, data sources and other technical details are reported in an appendix at the end of the paper.

\section{MODEL}

The model is a relatively simple two-country dynamic stochastic general equilibrium (DSGE) economy with production, nominal rigidity in local currency, complete international financial markets, and so-called news shocks. Except for news shocks, the model and its solution are standard.

There are two equally sized and perfectly symmetric countries, Home and Foreign, and we denote quantities and prices in Foreign with an asterisk, *. In each country, there are two exogenous processes, for money supply and total factor productivity, and we assume that agents can receive new information about these processes one period in advance. Firms are monopolistic competitors that use

\footnotetext{
${ }^{7}$ Because of the definition of 'relative' and 'exchange rate' in their model, the claim has the opposite "sign" in their paper-i.e., this correlation has a negative sign.

${ }^{8}$ Rigobon and Sack (2004) is a notable exception.
} 
a linear technology with no capital. All goods are traded, but markets are segmented. Goods prices are set one period in advance in the currency of the final consumer (we assume staggered prices in an extension). International financial markets are complete in nominal terms. This is crucial because it allows us to study asset price behavior independently of portfolio allocations. Under complete markets, equity prices are the present discounted sum of future profits and are easily priced ruling out bubble solutions. In the rest of this section, we describe the model setup in more detail. Its full solution is reported in the appendix.

\section{A. Households}

The representative Home household $j$ maximizes

$$
\mathrm{E}_{t} \max _{C_{t}(j), \frac{M_{t}(j)}{P_{t}}, L_{t}(j), \cdots} \sum_{s=t}^{\infty} U\left(C_{s}(j), \frac{M_{t}(j)}{P_{t}}, L_{s}(j)\right),
$$

subject to a budget constraint (5) below, where $U$ is a well-defined period utility function, $C_{t}(j)$ is the consumption basket, $\frac{M_{t}(j)}{P_{t}}$ is real money balance, and $L_{t}(j)$ is the labor supply.

We assume the following period utility function:

$$
U\left(C_{s}(j), \frac{M_{t}(j)}{P_{t}}, L_{s}(j)\right)=\frac{C_{s}(j)^{1-\rho}}{1-\rho}+\frac{\kappa_{1}}{1-\varepsilon}\left(\frac{M_{s}(j)}{P_{s}}\right)^{1-\varepsilon}-\frac{\kappa_{2}}{1+\psi} L_{s}(j)^{1+\psi}
$$

where $\rho>0, \varepsilon>0$, and $\psi \geq 0$ are elasticities, and $\kappa_{1}$ and $\kappa_{2}$ are some positive constants. The consumption basket $C_{t}(j)$ is defined as

$$
C_{t}(j) \equiv\left[\left(\frac{1}{2}\right)^{1 / \omega} C_{h, t}(j)^{(\omega-1) / \omega}+\left(\frac{1}{2}\right)^{1 / \omega} C_{f, t}(j)^{(\omega-1) / \omega}\right]^{\omega /(\omega-1)},
$$

where $\omega>0$ is the elasticity of substitution between Home and Foreign produced goods. The consumption baskets of Home and Foreign produced goods, $C_{h, t}$ and $C_{f, t}$, are respectively

$$
\begin{aligned}
C_{h, t}(j) & \equiv\left[\frac{1^{-1 / \lambda}}{2} \int_{0}^{\frac{1}{2}} C_{h, t}(j, i)^{(\lambda-1) / \lambda} d i\right]^{\lambda /(\lambda-1)}, \\
C_{f, t}(j) & \equiv\left[\frac{1}{2}^{-1 / \lambda} \int_{\frac{1}{2}}^{1}, C_{f, t}(j, i)^{(\lambda-1) / \lambda} d i\right]^{\lambda /(\lambda-1)},
\end{aligned}
$$

where $\lambda>1$ denotes the elasticity of substitution among different varieties. Given these baskets, the aggregate price index can be written as

$$
P_{t}=\left[\frac{1}{2} P_{h, t}^{1-\omega}+\frac{1}{2} P_{f, t}^{1-\omega}\right]^{1 /(1-\omega)}
$$

where

$$
P_{h, t}=\left[2 \int_{0}^{\frac{1}{2}} P_{h, t}(i)^{1-\lambda} d i\right]^{1 /(1-\lambda)}, \quad P_{f, t}=\left[2 \int_{\frac{1}{2}}^{1} P_{f, t}(i)^{1-\lambda} d i\right]^{1 /(1-\lambda)}
$$


with $P_{h, t}(i)$ denoting the nominal price of Home good $i$, and $P_{f, t}(i)$ the price of Foreign traded good $i$ sold in the Home market.

Asset markets are complete in nominal terms. Thus, the the budget constraint can be written as

$$
P_{t} C_{t}+M_{t}+P J_{t, t+1}^{\prime} J_{t+1}=W_{t} L_{t}+M_{t-1}+P J_{t, t}^{\prime} J_{t}+T_{t},
$$

where $J_{t}$ is a vector of contingent securities that complete the markets, $P J_{t, t}$ denotes a vector of payoffs from $J_{t}$ at time $t$, and $P J_{t, t+1}$ is the cost of purchasing these securities between period $t$ and $t+1$, and $T_{t}$ is a lump-sum transfer from the government generated by seignorage.

Given prices and the total consumption basket $C_{t}$, the optimal consumption allocations satisfy (since households are identical, we can suppress the index $j$ ):

$$
\begin{aligned}
C_{h, t}(i) & =2\left(\frac{P_{h, t}(i)}{P_{h, t}}\right)^{-\lambda} C_{h, t}, & C_{f, t}(i) & =2\left(\frac{P_{f, t}(i)}{P_{f, t}}\right)^{-\lambda} C_{f, t} \\
C_{h, t} & =\frac{1}{2}\left(\frac{P_{h, t}}{P_{t}}\right)^{-\omega} C_{t}, & C_{f, t} & =\frac{1}{2}\left(\frac{P_{f, t}}{P_{t}}\right)^{-\omega} C_{t} .
\end{aligned}
$$

Labor supply is

$$
W_{t}=\kappa_{2} \frac{L_{t}^{\psi}}{C_{t}^{-\rho} / P_{t}}
$$

while money demand is given by

$$
\left(\frac{M_{t}}{P_{t}}\right)^{\varepsilon}=\kappa_{1} \frac{C_{t}^{\rho}}{1-\mathrm{E}_{t} \beta D_{t, t+1}}
$$

where

$$
D_{t, t+s}=\frac{C_{t+s}^{-\rho} / P_{t+s}}{C_{t}^{-\rho} / P_{t}}
$$

is the stochastic discount factor or the Home currency pricing kernel.

As it is known, under a complete asset market structure in nominal terms, and full symmetry between the Home and Foreign economy, we have:

$$
\frac{S_{t} P_{t}^{*}}{P_{t}}=\frac{U_{c}\left(C_{t}^{*}\right)}{U_{c}\left(C_{t}\right)} .
$$

Note also that, under the assumption of complete markets, given the discount factor, the price, $Z_{t}$, of any security whose payoff at any future date $t+s$ is $C F_{t+s}$, in Home currency, is given by

$$
Z_{t}=\sum_{s=0}^{\infty} \beta^{s} D_{t, t+s} C F_{t+s} .
$$




\section{B. Firms}

Firms are monopolistic competitors with a linear technology in labor:

$$
Y_{t}(i)=A_{t} L_{t}(i)
$$

where $Y_{t}(i)$ is firm $i$ 's production, $L_{t}(i)$ is firm $i$ 's labor input, and $A_{t}$ is Home productivity, common across all Home firms.

Firms supply goods as demanded. This in turn determines labor demand. We assume that international good markets are segmented, and a firm $i$ presets its prices for the Home market, $P_{h, t}(i)$, and the Foreign market, $P_{h, t}^{*}(i)$, in local currencies (LCP).

Firms set prices one period in advance. ${ }^{9}$ The price is set to maximize its discounted profit, given other firms' prices. The discounted profit for firm $i$ is

$$
D_{t-1, t} \Pi_{t}(i)=D_{t-1, t}\left[P_{h, t}(i) Y_{h, t}(i)+S_{t} P_{h, t}^{*}(i) Y_{h, t}^{*}(i)-W_{t} L_{t}(i)\right]
$$

where the Home and Foreign demands for firm $i$ 's good are, respectively,

$$
\begin{aligned}
& Y_{h, t}(i)=\left(\frac{P_{h, t}(i)}{P_{h, t}}\right)^{-\lambda}\left(\frac{P_{h, t}}{P_{t}}\right)^{-\omega} C_{t} \\
& Y_{f, t}(i)=\left(\frac{P_{h, t}^{*}(i)}{P_{h, t}^{*}}\right)^{-\lambda}\left(\frac{P_{h, t}^{*}}{P_{t}^{*}}\right)^{-\omega} C_{t}^{*} .
\end{aligned}
$$

Thus, the optimal prices for the two markets are

$$
\begin{aligned}
& P_{h, t}(i)=\frac{\lambda}{\lambda-1} \frac{\mathrm{E}_{t-1} D_{t-1, t} \frac{W_{t}}{A_{t}} C_{t}}{\mathrm{E}_{t-1} D_{t-1, t} C_{t}} \\
& P_{h, t}^{*}(i)=\frac{\lambda}{\lambda-1} \frac{\mathrm{E}_{t-1} D_{t-1, t} \frac{W_{t}}{A_{t}} C_{t}^{*}}{\mathrm{E}_{t-1} D_{t-1, t} C_{t}^{*} S_{t}} .
\end{aligned}
$$

Since all firms are homogenous, $P_{h, t}(i)=P_{h, t}$ for all $i$. Foreign firms are characterized by a fully symmetric set of equations and assumptions.

\section{Market Clearing and Equilibrium}

Labor and goods markets clear as follows:

$$
\begin{aligned}
& Y_{t}=A_{t} L_{t} \\
& Y_{t}=\frac{1}{2}\left(\frac{P_{h, t}}{P_{t}}\right)^{-\omega} C_{t}+\frac{1}{2}\left(\frac{P_{h, t}^{*}}{P_{t}^{*}}\right)^{-\omega} C_{t}^{*}
\end{aligned}
$$

\footnotetext{
${ }^{9}$ In an extension of the model in section 4, we assume quadratic adjustment costs a la Rotemberg (1982).
} 
Given good prices, households satisfy the first order conditions, equations (6) and (7). The money market clears equating money demand from the households' first order conditions and money supply as specified below. In the initial state, we assume that $A_{0}=A_{0}^{*}=1$ and $P_{0}=P_{0}^{*}=S_{0}=1$. This will in turn determines initial values for $M_{0}=M_{0}^{*}$. We also assume that there is no news about the future at time 0 . Given exogenous processes for productivity and money supply, equilibrium is defined as usual.

\section{Stochastic Processes and Information Assumptions}

The assumptions on the stochastic processes driving the model dynamics are novel. While these assumptions yield interesting implications for exchange rate and equity price dynamics, solving the model remains manageable. We assume that productivity levels, $\ln \left(A_{t}\right)$ and $\ln \left(A_{t}^{*}\right)$, have a unit root but share a common stochastic trend, and thus cointegrate. Specifically, the difference between the logarithm of Home and Foreign productivity follows a stationary, mean reverting process, while world productivity, defined as average of the logarithm of Home and Foreign productivity, follows a random walk without drift: ${ }^{10}$

$$
\begin{aligned}
a_{t}^{R} & \equiv \ln \left(A_{t}\right)-\ln \left(A_{t}^{*}\right)=\theta a_{t-1}^{R}+\nu_{1, t}^{R}+\nu_{2, t-1}^{R} \\
a_{t}^{W} & \equiv \frac{1}{2}\left[\ln \left(A_{t}\right)+\ln \left(A_{t}^{*}\right)\right]=a_{t-1}^{W}+\nu_{1, t}^{W}+\nu_{2, t-1}^{W}
\end{aligned}
$$

where $|\theta|<1$ and $\left(\begin{array}{c}\nu_{1, t} \\ \nu_{2, t}\end{array}\right)$ are jointly i.i.d. over time with mean zero and the following variance-covariance matrix $\left(\begin{array}{cc}\sigma_{\nu 1}^{2} & \varrho_{a} \sigma_{\nu 1} \sigma_{\nu 2} \\ \varrho_{a} \sigma_{\nu 1} \sigma_{\nu 2} & \sigma_{\nu 2}^{2}\end{array}\right)$. In this specification, $\nu_{1, t}$ is a traditional productivity shock, which we call a "current shock", while $\nu_{2, t}$ is a news shock that provides information about productivity one period in advance, i.e., on $a_{t+1}$. We assume a two-component process for productivity consistent with the solution approach we follow. This has the additional advantage of permitting to investigate the effects of both a persistent mean-reverting process and a unit root process on asset prices. ${ }^{11}$ Note that we can build a similar model assuming serially correlated error terms without news shocks and generate even higher asset price volatility than in our model with news shocks. But we prefer to distinguish news about the future, $\nu_{2, t}$, from current shocks, $\nu_{1, t}$, to better illustrate the mechanism through which persistence in standard productivity processes induces higher asset price volatility.

\footnotetext{
${ }^{10}$ Superscript $W$ denotes the world average of log deviations, and superscript $R$ denotes relative variables, defined as the difference between Home and Foreign. Note that the relative values of nominal variables such as profit (or inflation) are the difference between the log deviation of Home profits in Home currency and the log deviation of Foreign profits in Foreign currency. Returns on equities are also denominated in firm currency rather than investor currency unless otherwise noted.

${ }^{11}$ Engel and Matsumoto (2008) set up world and relative productivity processes in this way. Typically, in the international business cycle literature, e.g., Backus, Kehoe, and Kydland (1992), detrended productivity levels are assumed to follow stationary autoregressive process and we follow this assumption in our extended model presented in the next section for consistence with other studies.
} 
For the money supply, we assume the following processes:

$$
\begin{aligned}
\ln \left(M_{t}\right) & =\ln \left(M_{t-1}\right)+\mu_{t} \\
\ln \left(M_{t}^{*}\right) & =\ln \left(M_{t-1}^{*}\right)+\mu_{t}^{*}
\end{aligned}
$$

where $\mu_{t}$ is

$$
\begin{aligned}
& \mu_{t}^{R}=\nu_{3, t}^{R}+\nu_{4, t-1}^{R}+\chi_{1}^{R} \nu_{1, t}^{R}+\chi_{2}^{R} \nu_{2, t-1}^{R}+\chi_{3}^{R} \nu_{2, t}^{R}, \\
& \mu_{t}^{W}=\nu_{3, t}^{W}+\nu_{4, t-1}^{W}+\chi_{1}^{W} \nu_{1, t}^{W}+\chi_{2}^{W} \nu_{2, t-1}^{W}+\chi_{3}^{W} \nu_{2, t}^{W}
\end{aligned}
$$

with $\left(\begin{array}{c}\nu_{3, t} \\ \nu_{4, t}\end{array}\right)$ jointly i.i.d. over time, with mean zero and the variance-covariance matrix $\left(\begin{array}{cc}\sigma_{\nu 3}^{2} & \varrho_{m} \sigma_{\nu 3} \sigma_{\nu 4} \\ \varrho_{m} \sigma_{\nu 3} \sigma_{\nu 4} & \sigma_{\nu 4}^{2}\end{array}\right)$, and independent from $\nu_{1, t}$ and $\nu_{2, t}$.

Here, $\nu_{3, t}$ and $\nu_{4, t}$ are traditional shocks to the current period money stock and the news shock about next period's money stock, respectively, while $\chi_{1}, \chi_{2}$, and $\chi_{3}$ are monetary policy responses to current and future technology shocks. This implies that $\chi_{2} \nu_{2, t-1}$ is the delayed monetary policy response to the productivity news shock. ${ }^{12}$ These monetary policy responses are neither realistic nor optimal in this fully symmetric economy, but the setup highlights the linkage between the monetary policy response to different shocks and asset prices. However, in a numerically solved extension of the model, we show that the assumption that monetary policy follows a standard Taylor rule induce a monetary policy reaction to relative productivity shocks consistent with this specification.

For ease of interpretation of the results in the next section, it is useful to define the following variables:

$$
\begin{array}{ll}
\mu_{1, t}^{R} \equiv \nu_{3, t}^{R}+\chi_{1}^{R} \nu_{1, t}+\chi_{3}^{R} \nu_{2, t}^{R}, & \mu_{2, t}^{R} \equiv \nu_{4, t}^{R}+\chi_{2}^{R} \nu_{2, t}^{R}, \\
\mu_{1, t}^{W} \equiv \nu_{3, t}^{W}+\chi_{1}^{W} \nu_{1, t}+\chi_{3}^{W} \nu_{2, t}^{W}, & \mu_{2, t}^{W} \equiv \nu_{4, t}^{W}+\chi_{2}^{W} \nu_{2, t}^{W}
\end{array}
$$

so that

$$
\mu_{t}^{R}=\mu_{1, t}^{R}+\mu_{2, t-1}^{R}, \quad \mu_{t}^{W}=\mu_{1, t}^{W}+\mu_{2, t-1}^{W} .
$$

where $\mu_{1, t}^{R}$ or $\mu_{1, t}^{W}$ are the surprise components of the money supply, or the unanticipated policy changes, and $\mu_{2, t}^{R}$ or $\mu_{2, t}^{W}$ are news about future money supply including delayed policy responses to the news about future productivity.

\section{Solution AND Properties}

We solve the model by log-linearizing around an initial fully symmetric steady state. For any variable, lower case stands for its log-deviation from the initial symmetric steady state. The appendix reports a complete model solution. In the rest of this section, we discuss the implications of the model's solution for exchange rates and equity prices.

\footnotetext{
${ }^{12}$ We assume $\chi_{2} \chi_{3}=0$ so that monetary policy does not react to the same shock in two consecutive periods. In a technical appendix available from the authors, we report some of the results without assuming $\chi_{2} \chi_{3}=0$.
} 


\section{A. News Shock and Exchange Rate Predictability}

News shocks help to understand why it is hard to predict exchange rates. From the solution of the linearized model, we obtain the following expression for the exchange rate:

$$
s_{t}=\mathrm{E}_{t-1} m_{t}^{R}+(1-\beta) \varepsilon \underbrace{\left(m_{t}^{R}-\mathrm{E}_{t-1} m_{t}^{R}\right)}_{\mu_{1, t}^{R}}+\beta \underbrace{\left(\mathrm{E}_{t} m_{t+1}^{R}-\mathrm{E}_{t-1} m_{t}^{R}\right)}_{\mu_{1, t}^{R}+\mu_{2, t}^{R}} .
$$

Thus, the exchange rate depends only on the relative money supply, but the relative money supply is affected by both monetary and productivity shocks, because $\left(m_{t}^{R}-\mathrm{E}_{t-1} m_{t}^{R}\right)=\mu_{1, t}^{R}$ and $\left(\mathrm{E}_{t} m_{t+1}^{R}-\mathrm{E}_{t-1} m_{t}^{R}\right)=\mu_{1, t}^{R}+\mu_{2, t}^{R}$, where $\mu_{1, t}^{R}$ represents a combination of current shocks to productivity and the money stock and $\mu_{2, t}^{R}$ represents news shocks. Without news shocks, so that $\mu_{2, t}^{R}=0$, the expression above simplifies to $\left(\mathrm{E}_{t} m_{t+1}^{R}=m_{t}^{R}\right)$

$$
s_{t}=\mathrm{E}_{t-1} m_{t}^{R}+[(1-\beta) \varepsilon+\beta]\left(m_{t}^{R}-\mathrm{E}_{t-1} m_{t}^{R}\right) .
$$

This equation shows that the exchange rate depends on the past relative money supply, $\mathrm{E}_{t-1} m_{t}^{R}=m_{t-1}^{R}$, and the innovation in the relative money supply, $m_{t}^{R}-\mathrm{E}_{t-1} m_{t}^{R}$. Therefore, the surprise to the exchange rate, $s_{t}-\mathrm{E}_{t-1} s_{t}$, is $[(1-\beta) \varepsilon+\beta]$ times larger than the surprise to the relative money supply. Since $\varepsilon$ is thought to be close to one, if we happen to know the fundamental, we should also be able to predict the exchange rate. However, Meese and Rogoff (1983), and a very large literature after them, found this is clearly not the case.

In contrast, with news shocks, the model provides an explanation of the findings of Meese and Rogoff (1983), whose evaluation of exchange rate models is based on the realized current value of fundamentals. With news shocks, the model also highlights an inherent property of asset prices, namely their heavy dependence on future information, consistent with Engel, Mark, and West (2007) who find that news shocks indeed affect exchange rates. If agents have information about future monetary policy one period in advance (and $\nu_{3, t}=0, \chi_{1}=0$, and $\chi_{3}=0$ ), the exchange rate is still hard to predict using current fundamentals, but this is no longer puzzling with news shocks. With news shocks the realization of the relative money supply is known one period in advance, i.e., $m_{t}^{R}=\mathrm{E}_{t-1} m_{t}^{R}$, and there is no surprise to it, so that the exchange rate depends on the current and future relative money supply, with a weight on the future money supply which is much larger than that on the current money supply, as the discount factor $(\beta)$ is typically close to one:

$$
s_{t}=(1-\beta) m_{t}^{R}+\beta \mathrm{E}_{t} m_{t+1}^{R} .
$$

In this case, the surprise to the exchange rate is

$$
s_{t}-\mathrm{E}_{t-1} s_{t}=(1-\beta)\left(m_{t}^{R}-\mathrm{E}_{t-1} m_{t}^{R}\right)+\beta\left(\mathrm{E}_{t} m_{t+1}^{R}-\mathrm{E}_{t-1} m_{t+1}^{R}\right),
$$

as $\mathrm{E}_{t} m_{t+1}^{R}-\mathrm{E}_{t-1} m_{t+1}^{R}=\mu_{2, t}^{R}$ is different from zero. Since agents know the future value of the money supply, and the exchange rate largely depends on this rather than its current value, it becomes evident that knowing the current of the fundamental is not enough to predict exchange rates with news shocks. 


\section{B. Exchange Rate Volatility}

In general, in our model with news shocks, the conditional variance of the exchange rate can exceed the conditional variance of the relative money supply for any $\varepsilon \geq 1$. From the model's solution, we have the following expression for the conditional variance of the exchange rate:

$$
\operatorname{Var}_{t-1} s_{t}=[(1-\beta) \varepsilon+\beta]^{2} \operatorname{Var}_{t-1} m_{t}^{R}+\beta^{2} \operatorname{Var}\left(\mu_{2}^{R}\right)
$$

where $\operatorname{Var}_{t-1} z_{t} \equiv \mathrm{E}\left(z_{t}-\mathrm{E}_{t-1} z_{t}\right)^{2}$ is the time $t-1$ conditional variance for any variable $z$, and $\operatorname{Var}(\cdot)$ is the corresponding unconditional variance. This expression shows that if there are news shocks about the future money supply, or there is a monetary reaction to news about future productivity, then $\operatorname{Var}\left(\mu_{2}^{R}\right)>0$, and the result follows. However, the challenge for a general equilibrium model with asset prices is to generate realistic volatility relative to the unconditional variance of the fundamentals, e.g., the relative money supply in our case. ${ }^{13}$

News shocks can generate excess volatility with respect to the unconditional variance of the fundamentals if they are correlated with current shocks. To see this, assume for simplicity that there is no monetary response to productivity shocks, then the unconditional variance of relative money supply growth is

$$
\operatorname{Var}\left(\Delta m_{t}^{R}\right)=\operatorname{Var}\left(\nu_{3, t}^{R}+\nu_{4, t-1}^{R}\right)=\sigma_{\nu 3}^{2}+\sigma_{\nu 4}^{2} .
$$

In this case, the conditional variance of the exchange rate is

$$
\begin{aligned}
\operatorname{Var}_{t}\left(\Delta s_{t}^{R}\right) & =\operatorname{Var}\left([(1-\beta) \varepsilon+\beta] \nu_{3, t}^{R}+\beta \nu_{4, t}^{R}\right) \\
& =[(1-\beta) \varepsilon+\beta]^{2} \sigma_{\nu_{3}^{R}}^{2}+\beta^{2} \sigma_{\nu_{4}^{R}}^{2}+2[(1-\beta) \varepsilon+\beta] \beta \varrho_{m} \sigma_{\nu_{3}^{R}} \sigma_{\nu_{4}^{R}} .
\end{aligned}
$$

If $\varepsilon=1$, as it is often assumed, we need $\varrho_{m}>\frac{1-\beta^{2}}{2 \beta} \frac{\sigma_{\nu_{4}^{R}}}{\sigma_{\nu_{3}^{R}}}>0$ in order for the exchange rate return to be more volatile than the money supply growth. For example, consider the following two cases: $\sigma_{\nu_{3}^{R}}^{2}=.5, \sigma_{\nu_{4}^{R}}^{2}=.5, \beta=0.95, \varrho_{m}=0.6$ and $\sigma_{\nu_{3}^{R}}^{2}=1, \sigma_{\nu_{4}^{R}}^{2}=0$. The variance of the relative money supply growth the same (one) in both cases. However $\operatorname{Var}_{t}\left(\Delta s_{t}^{R}\right)=1.545$ in the first case, while $\operatorname{Var}_{t}\left(\Delta s_{t}^{R}\right)=1$ in the second case.

There are two offsetting forces driving this result. The first is $\nu_{4}^{R}$ that provides accurate news about future, which reduces the variance of exchange rate (the proposition of West (1988)). ${ }^{14}$ The second is the positive correlation between news shocks and current shocks, which alters the underlying stochastic process for the relative money supply growth but keeps its unconditional variance unchanged. Because of this positive correlation, today's news about the future relative money supply growth has an information content that is similar to that of today's shocks to the relative money

\footnotetext{
${ }^{13}$ As exchange rate returns are hard to predict, the conditional and unconditional volatility of exchange rates are usually very close in the data. In the model, since the conditional variance is smaller than the unconditional variance, we focus on the relation between the conditional variance of the asset and the unconditional variance of the money supply and productivity.

${ }^{14}$ West (1988) has shown that, given the underlying stochastic process, such as a process for the money supply in our model, giving news to agents reduces asset price volatility. Our result is fully consistent with West's (1988). If agents do not know $\nu_{4, t}^{R}$ but do know the underlying process, then they can guess $\nu_{4, t}^{R}$ with some error. In this case, there will be more volatility than the case in which agents know precisely $\nu_{4, t}^{R}$.
} 
supply growth. And this moves the exchange rate more in the same direction than the case in which current and news shocks are uncorrelated, thereby busting exchange rate volatility.

To see this in a different way, note that

$$
\Delta s_{t}-\mathrm{E}_{t-1} \Delta s_{t}=[(1-\beta) \varepsilon+\beta] \nu_{3, t}^{R}+\beta \nu_{4, t}^{R} .
$$

The surprise to the exchange rate returns depends on current and news shocks. We can now easily see that if $\nu_{3, t}^{R}$ and $\nu_{4, t}^{R}$ are positively correlated, then the exchange rate moves more in one direction at time $t$ than in the case in which $\nu_{3, t}^{R}$ and $\nu_{4, t}^{R}$ are uncorrelated. In contrast, the volatility of relative money growth, $\Delta m_{t}^{R}=\nu_{3, t}^{R}+\nu_{4, t-1}^{R}$, will not be affected by positive correlation between $\nu_{3, t}^{R}$ and $\nu_{4, t}^{R}$ because $\nu_{3, t}^{R}$ and $\nu_{4, t-1}^{R}$ are independent. Exchange rates will therefore be more volatile than their fundamentals in this case.

What does this correlation mean in general? Correlated news shocks provide an economic interpretation of the impact of persistent underlying processes on asset price volatility. A persistent stochastic process tends to increase asset price volatility because persistence provides a "noisy" news about the future, which is similar to today's surprise. ${ }^{15}$ For instance, interest rate smoothing implies that a positive (negative) interest rate change today will persist tomorrow, and thus the current shock signals news about future interest rate changes. ${ }^{16}$ What matters for asset price volatility is future information. This is regardless of whether agents have accurate information about the future, formulate rational expectation about this information, or it is news shocks positively correlated with surprise to current fundamentals. News shocks, therefore, helps to understand not only the lack of exchange rate predictability but also why persistent underlying processes generate excess volatility.

In our model, news shocks are only about one-period-ahead information, and thus their impact on asset price volatility is bound to be limited. However, if news shocks provide information about several periods ahead, the effect of positive correlation with current shocks would be much larger because agents would update the entire future path of the fundamentals in the same direction, even if the two sets of shocks were independent over time. ${ }^{17}$

The result above is general. Any asset price that is the discounted sum of future fundamentals has a similar property. Consider for example the following generic cash flow claim:

$$
z_{t}=\sum_{s=0}^{\infty} \beta^{s} E_{t} c f_{t+s} .
$$

If, at time $t$, an uni-directional update of $\left\{c f_{t+s}\right\}_{s=0}^{\infty}$ takes place, then $z_{t}$ moves a lot in the same direction. But this does not mean that $\Delta c f_{t}$ moves more because it is the sum of news and current shocks over time, which are assumed to be i.i.d. Recall in fact that, in the case of the exchange rate

\footnotetext{
${ }^{15}$ We study formally the role of persistence in the underlying process for volatility of equity returns in the next subsection. In section 4, we also compare numerically the effect of interest rate smoothing and correlated news shocks.

${ }^{16}$ Interestingly, this can explain why Chari, Kehoe, and McGrattan (2002), Monacelli (2004), and Groen and Matsumoto (2004) generate higher exchange rate volatility with interest rate smoothing.

${ }^{17}$ Another limitation of our simple model is that, without real frictions, some of the fundamental variables in the model can be quite volatile. For example, as $c_{t}^{R}=\frac{1}{\rho}\left(s_{t}-p_{t}^{R}\right)$ in the model's solution, relative consumption is quite volatile. This point is illustrated explicitly in the later subsection on world equity returns.
} 
and the money supply, the exchange rate change is affected by both $\nu_{3, t}^{R}$ and $\nu_{4, t}^{R}$, the shocks at time $t$, while the money growth is sum of $\nu_{3, t}^{R}$ and $\nu_{4, t-1}^{R}$, that is, shocks realized at different time periods, $t$ and $t-1$. Therefore, this contemporaneous correlation increases volatility of asset prices without affecting the volatility of the underlying process.

\section{Equity Return Volatility}

Equities in our model are claims that pay off the firms' profits every period. Firms do not have physical capital, but they have monopolistic power and can generate profit in our model. If we apply the pricing equation (12) ruling out the bubble solution, we obtain the following expression for the pre-dividend price of this claim:

$$
q_{t}=\beta \mathrm{E}_{t} q_{t+1}+(1-\beta) \pi_{t}-\beta i_{t},
$$

where $i_{t}=E_{t}\left(-d_{t, t+1}\right)$ is the (linearized) nominal interest rate between period $t$ to $t+1$. Then, it is straightforward to derive the following expression for the return on equity ${ }^{18}$

$$
r_{t+1}=i_{t}+\left(q_{t+1}-\mathrm{E}_{t} q_{t+1}\right)
$$

The analysis of equity return volatility is slightly more complex than that of exchange rate volatility, although, as we shall see, the role of news shocks for equity price dynamics is analogous. One important difference is due to the fact that the equity return depends on both world and country specific shocks. Without loss of generality, in order to simplify the analysis, we therefore focus on the world return and the relative return separately. A second difference is that equity price dynamics depends on the currency denomination of the firm profit. For this reason, we distinguish between the relative return on equity denominated in the currency of local firms and the currency of a representative Home or Foreign investor.

World Equity Return The role of news shocks correlated with current shocks for world excess equity returns is the same as we discussed for exchange rate volatility. Given our definition of relative and world variables, the excess return on Home equity over the Home interest rate is

$$
r_{t+1}-i_{t}=\left(r_{t+1}^{W}-i_{t}^{W}\right)+\frac{1}{2}\left(r_{t+1}^{R}-i_{t}^{R}\right)
$$

\footnotetext{
${ }^{18}$ Notice that the return on equity is not i.i.d., as the nominal interest rate is known at time $t$, but its excess return over the nominal interest rate is indeed an i.i.d. process as one would expect.
} 
Consider the world excess return: ${ }^{19}$

$$
\begin{aligned}
& r_{t+1}^{W}-i_{t}^{W} \\
= & \left\{\rho\left(1-\frac{1}{\varepsilon}\right)+(1-\rho)\left[1+(1-\beta)\left(1-\frac{1}{\varepsilon}\right)\right]\right\} \beta \frac{\psi+1}{\rho+\psi}\left(\nu_{1, t+1}^{W}+\nu_{2, t+1}^{W}\right) \\
& +(1-\beta) \frac{\zeta}{1-\zeta}(\psi+1)\left[\nu_{1, t+1}^{W}-\beta\left(1-\frac{1}{\varepsilon}\right)\left(\nu_{1, t+1}^{W}+\nu_{2, t+1}^{W}\right)\right] \\
& +\left[1+(1-\beta) \frac{1-\rho}{\rho}-(1-\beta) \frac{\zeta}{1-\zeta} \frac{\rho+\psi}{\rho}\right]\left[(1-\beta) \varepsilon\left(\mu_{1, t+1}^{W}\right)+\beta\left(\mu_{1, t+1}^{W}+\mu_{2, t+1}^{W}\right)\right]
\end{aligned}
$$

From this expression, we can see first that news shocks about future productivity affect the world excess return, unless both $\varepsilon=1$ and $\rho=1$, which is not a likely parameter value combination.

Notice then that, compared to the unconditional variance of productivity growth,

$$
\operatorname{Var}\left(\Delta a_{t+1}^{W}\right)=\operatorname{Var}\left(\nu_{1, t+1}^{W}+\nu_{2, t}^{W}\right)=\sigma_{\nu 1}^{2}+\sigma_{\nu 1}^{2},
$$

the variance of $\left(r_{t+1}^{W}-i_{t}^{W}\right)$ depends on the correlation between $\nu_{1, t+1}^{W}$ and $\nu_{2, t+1}^{W}, \varrho_{a}$. This is because the world excess return is affected by both the current shock and the news shock at time $t+1, \nu_{1, t+1}$ and $\nu_{2, t+1}$, respectively. This implies that the ratio of the variance of the world excess return relative to that of the world productivity growth is increasing in $\varrho_{a}$. The same is true with respect to current and news monetary policy shocks, which are represented by $\mu_{1, t+1}^{W}$ and $\mu_{2, t+1}^{W}$. News shocks correlated with current shocks play the same role for world excess equity returns that they play for exchange rate volatility.

The solution for the world excess return illustrates the transmission mechanism of policy news. Policy news shocks affect the world excess return if and only if current monetary policy shocks affect it. This is because $\mu_{1, t+1}^{W}$ and $\mu_{2, t+1}^{W}$ share the same coefficient in equation (33), and for either of them to have an impact it must be the case that $\left[1+(1-\beta) \frac{1-\rho}{\rho}-(1-\beta) \frac{\zeta}{1-\zeta} \frac{\rho+\psi}{\rho}\right] \neq 0$. This implies that it is difficult to measure the impact of monetary policy on equity prices through event studies of actual policy changes.

The typical event study uses the change in adjusted federal funds rate futures at the time of a FOMC announcement on the right hand side. This, in theory, captures current policy shocks, or $\mu_{1, t+1}$. FOMC announcements, however, often contain information about the future interest rates as well, $\mu_{2, t+1}$, and equity returns must reflect that information as well. If one regresses equity returns onto changes in federal funds rate futures, it may bias the estimate of the effect of current shocks because the effect of news about the future is omitted from the econometrician's specification. Interestingly, equation (33) suggests that a policy announcement affects equity return only at the time of announcement. So a monetary authority could potentially influence the stock market without changing current interest rates.

The analysis the solution for other variables highlights an important limitation of our relatively simple model of asset price volatility. While news shocks correlated with current shocks can increase equity return volatility without affecting the volatility of world productivity growth, this will also

\footnotetext{
${ }^{19}$ Because the Home interest rate is known at time $t$, it does not matter wether we look at excess or absolute returns. Also notice that world equity returns are not affected by the currency denomination of the profit.
} 
increase the conditional variance of other fundamental variables in the model, and particularly dividends and consumption. For instance, the surprise to dividends,

$$
\begin{aligned}
& \pi_{t}^{W}-\mathrm{E}_{t-1} \pi_{t}^{W} \\
= & c_{t}^{W}-\mathrm{E}_{t-1} c_{t}^{W}+\frac{\zeta}{1-\zeta}\left[(\psi+1)\left(a_{t}^{W}-\mathrm{E}_{t-1} a_{t}^{W}\right)-(\rho+\psi)\left(c_{t}^{W}-\mathrm{E}_{t-1} c_{t}^{W}\right)\right],
\end{aligned}
$$

depends on current productivity shocks and the current consumption surprise. Consumption, in turn, also depends on news shocks, with a variance which is increasing in the correlation between current and news shocks:

$$
\begin{aligned}
c_{t}^{W}= & \frac{1}{\rho}\left\{(1-\beta) \varepsilon\left(\mu_{1, t}^{W}\right)+\beta\left(\mu_{1, t}^{W}+\mu_{2, t}^{W}\right)\right\} \\
& +\frac{\psi+1}{\rho+\psi}\left\{\mathrm{E}_{t-1} a_{t}^{W}+\beta\left[1-\frac{1}{\varepsilon}\right]\left(\nu_{1, t}^{W}+\nu_{2, t}^{W}\right)\right\} .
\end{aligned}
$$

Nonetheless, our analysis illustrates one important mechanism through which more realistic volatility of equity returns can be generated in general equilibrium. ${ }^{20}$

Relative Equity Return Recall that, in general, relative equity price dynamics depends on the currency denomination of the firm's profit. For this reason, in this subsection, we look in turn at relative return on equity denominated in the currency of a representative Home or Foreign investor (which we label "the investor currency profit" or "profit in investor currency") and in the currency of local firms (which we label "the local currency profit" or "profit in local currency").

News shock correlated with current shocks unambiguously increase the volatility of relative equity returns in investor currency without affecting the volatility of relative productivity in a plausible range of parameter values. To see this, define the relative return on equity in investor currency as follows: ${ }^{21}$

$$
r_{t+1}^{R \$} \equiv r_{t+1}^{R}-\Delta s_{t+1}
$$

where

$$
r_{t+1}^{R}=r_{t+1}-r_{t+1}^{*}
$$

and

$$
\begin{aligned}
\Delta s_{t+1} & =s_{t+1}-s_{t} \\
& =[(1-\beta) \varepsilon+\beta] \mu_{1, t+1}^{R}+\beta \mu_{2, t+1}^{R}-(\varepsilon-1)(1-\beta) \mu_{1, t}^{R}+(1-\beta) \mu_{2, t}^{R} .
\end{aligned}
$$

Then, it is possible to show that

$$
\begin{aligned}
& r_{t+1}^{R \$}=r_{t+1}-\Delta s_{t+1} \\
& \quad=(1-\beta)(\psi+1)\left[\left(\frac{\omega-1}{\omega \psi+1} \frac{\beta \theta}{1-\beta \theta}+\frac{\zeta}{1-\zeta}\right) \nu_{1, t+1}^{R}+\frac{\omega-1}{\omega \psi+1} \frac{\beta}{1-\beta \theta} \nu_{2, t+1}^{R}\right]
\end{aligned}
$$

\footnotetext{
${ }^{20}$ For example, one can assume an exogenous dividend process.

${ }^{21}$ Notice that the residency of investors does not matter, since the relative return in Home currency is $r-\left(r^{*}+\Delta s\right)=r^{R}-\Delta s$ and the relative return in Foreign currency is $(r-\Delta s)-r^{*}=r^{R}-\Delta s$, where $r$ is defined above.
} 
This expression shows that $r_{t+1}^{R \$}$ depends only on current and news shocks to productivity, while monetary policy and the exchange rate do not affect it. In terms of volatility, we have the following expression for the unconditional variance of the relative return in investor currency:

$$
\begin{aligned}
& \operatorname{Var}\left(r_{t+1}^{R \$}\right) \\
= & {[(1-\beta)(\psi+1)]^{2}\left(\frac{\omega-1}{\omega \psi+1} \frac{\beta \theta}{1-\beta \theta}+\frac{\zeta}{1-\zeta}\right)^{2} \sigma_{\nu_{1}^{R}}^{2} } \\
& +2[(1-\beta)(\psi+1)]^{2}\left(\frac{\omega-1}{\omega \psi+1} \frac{\beta}{1-\beta \theta}\right)\left(\frac{\omega-1}{\omega \psi+1} \frac{\beta \theta}{1-\beta \theta}+\frac{\zeta}{1-\zeta}\right) \varrho_{a} \sigma_{\nu_{1}^{R}} \sigma_{\nu_{2}^{R}} \\
& +[(1-\beta)(\psi+1)]^{2}\left(\frac{\omega-1}{\omega \psi+1} \frac{\beta}{1-\beta \theta}\right)^{2} \sigma_{\nu_{2}^{R} .}^{2}
\end{aligned}
$$

First, let's examine this expression in relation to the unconditional variance of relative productivity, the fundamental determinant of the relative equity return in investor currency:

$$
\operatorname{Var}\left(a_{t}^{R}\right)=\frac{1}{1-\theta^{2}}\left(\sigma_{\nu_{1}^{R}}^{2}+\sigma_{\nu_{2}^{R}}^{2}+2 \theta \varrho_{a} \sigma_{\nu_{1}^{R}} \sigma_{\nu_{2}^{R}}\right)
$$

When $\theta=0$, the relation between the volatility of the relative equity return and relative productivity is the same as that between the exchange rate and the money supply volatility (although the variance of the money supply is in first difference in the case of the exchange rate). This implies that $\varrho_{a}>0$ can unambiguously increase the volatility of relative equity returns without affecting the volatility of relative productivity level.

When $\theta \neq 0$, both $\operatorname{Var}\left(a_{t}^{R}\right)$ and $\operatorname{Var}\left(r_{t+1}^{R \$}\right)$ can be large depending on the persistence parameter $\theta$. Indeed, variance ratio $\operatorname{Var}\left(r_{t+1}^{R \$}\right) / \operatorname{Var}\left(a_{t}^{R}\right)$ depends crucially on $\left(\frac{\beta \theta}{1-\beta \theta}\right)^{2} /\left(\frac{1}{1-\theta^{2}}\right)$ assuming $\omega \neq 1$. The latter expression has a local maximum for $0<\theta<1$, but it is increasing in $\theta$, for $\theta<\beta$. Therefore, a persistent relative productivity process tends to increase the volatility of the equity return differentials in investor currency relative to the volatility of the underlying productivity differential as long as $\theta<\beta$. However, when $\theta$ exceeds $\beta$, the effect of persistence on volatility starts to decline. ${ }^{22}$

Depending on the value of other parameters, equation (39) also shows that the relative equity return in investor currency may not be much more volatile than the relative dividend. In particular, if the elasticity of substitution between home and foreign goods, $\omega$, is unity then the relative return in firm currency becomes

$$
r_{t+1}^{R \$}=(1-\beta)(\psi+1) \frac{\zeta}{1-\zeta} \nu_{1, t+1}^{R},
$$

and news shocks have no impact in this case. This is because the terms of trade provides full risk sharing in this case and neutralize the effect of higher (lower) demand on firms revenue with lower (higher) producer prices. ${ }^{23}$

\footnotetext{
${ }^{22}$ We also illustrate the effect of persistence in the numerical simulations in the next section of the paper as the same mechanism applies in the case of interest rate smoothing and exchange rate volatility.

${ }^{23}$ This risk sharing mechanism works relatively well with $\omega$ close to unity. See the discussion in Engel and Matsumoto (2008).
} 
Consider now the equity return in firm local currency:

$$
r_{t+1}^{R}=\Delta s_{t+1}+r_{t+1}^{R \$}
$$

The impact of news shock correlated with current shocks on the volatility of relative equity returns in firm currency depends on the reaction of monetary policy to productivity shocks and is a quantitative matter. To see this, notice first that the relative return in firm local currency, $r_{t+1}^{R}$, as in Hau and Rey (2006), naturally depends on the exchange rate in our model. In equilibrium, in fact, the relative firm profit can be expressed as

$$
\begin{aligned}
\pi_{t}^{R} & \equiv \pi \text { (in Home currency) }-\pi^{*} \text { (in Foreign currency) } \\
& =s_{t}+(\psi+1)\left[\frac{\omega-1}{\omega \psi+1}\left(a_{t}^{R}-\nu_{1, t}^{R}\right)+\frac{\zeta}{1-\zeta} \nu_{1, t}^{R}\right]
\end{aligned}
$$

This expression shows that the relative firm profit depends on the exchange rate and on current productivity $\left(a_{t}^{R}\right)$ as well as its innovation $\left(\nu_{1, t}^{R}\right)$. The exchange rate enters this equation because the firms' revenues are denominated in the currency of their residency. News shocks at time $t$ do not affect relative profits directly, although they affect relative profits through exchange rate changes. (Lagged values of news shocks enter through $a_{t}^{R}$.) Notice also that, since $r_{t+1}^{R \$}$ depends only on i.i.d. shocks, $E_{t} r_{t+1}^{R \$}=0$. Thus,

$$
E_{t} r_{t+1}^{R}=E_{t} \Delta s_{t+1}\left(=i_{t}^{R}\right)
$$

This relation, which is an equity return version of the UIP, shows that the expected relative equity return in firm local currency is exactly the same as expected exchange rate change. Thus, in our model, the relative return in firm local currency naturally depends on exchange rate both in realization and expectation.

Given (41), the variance of $r_{t+1}^{R}$ depends on the comovement between the exchange rate and equity returns in investor currency, which is discussed in more detail in the next subsection. If there is no monetary policy response to productivity shocks, then the exchange rate is uncorrelated to $r_{t+1}^{R \$}$, because $r_{t+1}^{R \$}$ is a linear function of current and news shocks to productivity, as shown in equation (38). Thus, in this case,

$$
\operatorname{Var}\left(r_{t+1}^{R}\right)=\operatorname{Var}\left(\Delta s_{t+1}\right)+\operatorname{Var}\left(r_{t+1}^{R \$}\right) .
$$

This equation shows that the variance of the relative equity return in local currency will depend on the variance of both current and news shocks to productivity via $r_{t+1}^{R \$}$ as well as current and news shocks to the relative money supply via $\Delta s_{t+1}$. This is because $\operatorname{Var}\left(\Delta s_{t+1}\right)$ depends on the volatility of money supply shocks, while $\operatorname{Var}\left(r_{t+1}^{R \$}\right)$ depends on the volatility of productivity shocks. In addition, we saw earlier that both $\operatorname{Var}\left(\Delta s_{t+1}\right)$ and $\operatorname{Var}\left(r_{t+1}^{R \$}\right)$ increase, without affecting variances of underlying processes, if news shocks and current shocks in money supply and productivity are positively correlated. Thus, news shocks correlated with current shocks can unambiguously generate excess volatility relative to fundamentals also for the relative equity return in firm currency if monetary policy does not respond to productivity shocks.

More generally, however, when monetary policy responds to productivity shocks, the ability of news shocks correlated with current shocks to generate excess volatility is a quantitative matter. This is because, in this case, the sign and magnitude of $\operatorname{Cov}\left(\Delta s_{t+1}, r_{t+1}^{R \$}\right)$ depends on the monetary policy 
response to productivity shocks. Formally,

$$
\begin{aligned}
\operatorname{Var}\left(r_{t+1}^{R}\right) & =\operatorname{Var}\left(\Delta s_{t+1}\right)+2 \operatorname{Cov}\left(\Delta s_{t+1}, r_{t+1}^{R \$}\right)+\operatorname{Var}\left(r_{t+1}^{R \$}\right), \\
\operatorname{Var}_{t}\left(r_{t+1}^{R}\right) & =\operatorname{Var}\left(r_{t+1}^{R}-i_{t}^{R}\right)=\operatorname{Var}_{t}\left(\Delta s_{t+1}\right)+2 \operatorname{Cov}\left(\Delta s_{t+1}, r_{t+1}^{R \$}\right)+\operatorname{Var}\left(r_{t+1}^{R \$}\right),
\end{aligned}
$$

and the model can generate either a positive or negative covariance between exchange rate returns and relative equity returns in investor currency in this case.

\section{Exchange Rate and Equity Price Comovement}

The comovement between the exchange rate returns and the relative equity returns depends both on the currency denomination of the equity returns and the monetary policy reaction to productivity shocks. News shocks are not crucial to explain it.

If monetary policy does not respond to relative productivity shocks, that is the $\chi^{R}$ coefficients in (25) are zero, then we know from equation (27) that the exchange rate does not depend on relative productivity shocks. On the other hand, the relative return on equity in investor currency, $r_{t+1}^{R \$}$, does not depend on relative money supply shocks as we saw in equation (38). As a result, in this case, $\operatorname{Cov}\left(\Delta s_{t+1}, r_{t+1}^{R \$}\right)=0 .{ }^{24}$

However, if monetary policy does respond to productivity shocks, $\operatorname{Cov}\left(\Delta s_{t+1}, r_{t+1}^{R \$}\right) \neq 0$, and the sign of this correlation depends on whether or not monetary policy accommodate productivity shocks and on the variance of these shocks. ${ }^{25}$ Specifically, it can be shown that

$$
\begin{aligned}
& \operatorname{Cov}\left(\Delta s_{t+1}, r_{t+1}^{R \$}\right) \\
=(1 & -\beta)(\psi+1)\left(\frac{\omega-1}{\omega \psi+1} \frac{\beta \theta}{1-\beta \theta}+\frac{\zeta}{1-\zeta}\right)[1+(\varepsilon-1)(1-\beta)] \chi_{1}^{R} \operatorname{Var}\left(\nu_{1}\right) \\
& +(1-\beta)(\psi+1)\left(\frac{\omega-1}{\omega \psi+1} \frac{\beta}{1-\beta \theta}\right)[1+(\varepsilon-1)(1-\beta)] \chi_{3}^{R} \operatorname{Var}\left(\nu_{2}\right) \\
& +(1-\beta)(\psi+1)\left(\frac{\omega-1}{\omega \psi+1} \frac{\beta}{1-\beta \theta}\right) \beta \chi_{2}^{R} \operatorname{Var}\left(\nu_{2}\right)
\end{aligned}
$$

A positive productivity shock in a sticky price model typically induces a monetary policy loosening and a currency depreciation. Under this assumption, $\operatorname{Cov}\left(r_{t+1}^{R \$}, \Delta s_{t+1}\right)>0$. But if the monetary response to a productivity shock is not accommodative, this correlation can be negative too. ${ }^{26}$

The relative return on equity in firm currency, $r_{t+1}^{R}$, and its surprise component, $r_{t+1}^{R}-i_{t}^{R}$, naturally depends on the exchange rate in our model, as we showed in the previous subsection. If $\operatorname{Cov}\left(r_{t+1}^{R \$}, \Delta s_{t+1}\right)>0$, then we can see that $r_{t+1}^{R}$ too is positively correlated with the exchange rate, i.e.,

$$
\operatorname{Cov}\left(r_{t+1}^{R}, \Delta s_{t+1}\right)=\operatorname{Var}\left(\Delta s_{t+1}\right)+\operatorname{Cov}\left(r_{t+1}^{R \$}, \Delta s_{t+1}\right)>0
$$

\footnotetext{
${ }^{24}$ Note that, as $r_{t+1}^{R \$}$ is spanned by time $t+1$ variables, $\operatorname{Cov}\left(\Delta s_{t+1}, r_{t+1}^{R \$}\right)=\operatorname{Cov}_{t}\left(\Delta s_{t+1}, r_{t+1}^{R \$}\right)$.

${ }^{25} \mathrm{Here}$, we assume $\varrho_{a}=0$ and $\varrho_{m}=0$ for simplicity as these two correlations do not play an important role in this part of the analysis.

${ }^{26}$ We examine this case numerically in the next section.
} 
In addition, in this case, $r_{t+1}^{R}$ is more volatile than the exchange rate (as in the data) because ${ }^{27}$

$$
\operatorname{Var}_{t}\left(r_{t+1}^{R}\right)=\operatorname{Var}\left(r_{t+1}^{R}-i_{t}^{R}\right)=\operatorname{Var}_{t}\left(\Delta s_{t+1}\right)+\operatorname{Var}\left(r_{t+1}^{R \$}\right)+2 \operatorname{Cov}\left(r_{t+1}^{R \$}, \Delta s_{t+1}\right) .
$$

The model of Hau and Rey's (2006) also predicts a positive, but counterfactually perfect, correlation between the exchange rate and equity return in firm local currency, i.e., $\operatorname{Corr}\left(r_{t+1}^{R}, \Delta s_{t+1}\right)=1$ in their model. ${ }^{28}$ The main reason is that our model has more shocks, namely productivity shocks. In our model without a monetary policy reaction to productivity shocks,

$$
\begin{aligned}
\operatorname{Cov}\left(r_{t+1}^{R}, \Delta s_{t+1}\right) & =\operatorname{Var}\left(\Delta s_{t+1}\right) \\
\operatorname{Var}\left(r_{t+1}^{R}\right) & =\operatorname{Var}\left(\Delta s_{t+1}\right)+\operatorname{Var}\left(r_{t+1}^{R \$}\right)
\end{aligned}
$$

Hence,

$$
\operatorname{Corr}\left(r_{t+1}^{R}, \Delta s_{t+1}\right)=\frac{\operatorname{Var}\left(\Delta s_{t+1}\right)}{\sqrt{\operatorname{Var}\left(\Delta s_{t+1}\right)\left[\operatorname{Var}\left(\Delta s_{t+1}\right)+\operatorname{Var}\left(r_{t+1}^{R \$}\right)\right]}} \leq 1
$$

In contrast, the model of Hau and Rey (2006) has only one relative shock, and hence the relative equity return $r_{t+1}^{R}$ and $\Delta s_{t+1}$ are perfectly correlated. Indeed, as we shall see in the next section, this correlation is quite small in the data.

\section{Quantitative Analysis}

In this section, we extend the model, by adding staggered pricing and endogenous interest rate setting, and evaluate it quantitatively by comparing it to the data. After describing in more detail how we extend the model, we discuss some impulse responses to illustrate the transmission mechanism of current and news shocks. We then compare model-based second moments with the data.

\section{A. Model Extension and Calibration}

The complete extended version of the model is reported in the appendix. Here we describe only the two key ingredients that add some elements of realism and the model's calibration.

Staggered pricing To allow for partial price adjustment, we introduce menu costs a la Rotemberg (1983). ${ }^{29}$ Specifically, in order to change prices, firms have to pay quadratic costs of adjustment of the following form:

$$
Z^{P}=\frac{\alpha_{P}}{2}\left(\frac{P_{., t}(i)}{P_{., t-1}(i)}-1\right)^{2}
$$

\footnotetext{
${ }^{27}$ Note that, to have $\operatorname{Var}\left(r_{t+1}^{R}\right)>\operatorname{Var}\left(\Delta s_{t+1}^{R}\right)$, it is not necessary to have $\operatorname{Cov}\left(r_{t+1}^{R \$}, \Delta s_{t+1}\right)>0$. Indeed, this covariance is typically negative in the data as we report in Table 2.

${ }^{28} \mathrm{An}$ increase in $s_{t}$ implies a Home currency depreciation with our notation, whereas in the model of Hau and Rey (2006) an increase in $\mathrm{E}_{t}$ denotes a Foreign currency depreciation. Also $r_{t}^{R} \equiv r_{t}-r_{t}^{*}$ in our notation.

${ }^{29}$ We use this formulation to keep firm aggregation simple, but the log-linearized Phillips curve is isomorphic to that obtained with Calvo (1983) pricing. We also set parameter values to match price duration implied by the Calvo model.
} 
For example, the Home firm $i$ 's revenue in the Home market is

$$
\left(1-Z^{p}\right) P_{h, t}(i) Y_{h, t}(i)
$$

where

$$
Y_{h, t}(i)=\left(\frac{P_{h, t}(i)}{P_{h, t}}\right)^{-\lambda} C_{h, t} .
$$

Firms continue to price to market. So, for instance, Home firm $i$ maximizes the following: ${ }^{30}$

$$
\max _{P_{h, t}(i)} \mathrm{E}_{t} \sum_{s=0}^{\infty} \beta^{s} D_{t, t+s}\left\{\left(1-Z^{p}\right) P_{h, t+s}(i) Y_{h, t+s}(i)-\frac{W_{t+s}}{A_{t+s}} Y_{h, t+s}(i)\right\} .
$$

The first order condition for this problem is

$$
\begin{aligned}
& -\frac{\partial Z_{t}^{P}}{\partial P_{h, t}(i)} P_{h, t}(i) Y_{h, t}(i)+\left(1-Z^{P}\right) Y_{h, t}(i) \\
& -\lambda\left(1-Z^{P}\right) Y_{h, t}(i)+\lambda \frac{W_{t}}{A_{t}} \frac{Y_{h, t}(i)}{P_{h, t}(i)}-\mathrm{E}_{t} D_{t, t+1} \frac{\partial Z_{t+1}^{P}}{\partial P_{h, t}(i)} P_{h, t+1}(i) Y_{h, t+1}(i)=0 .
\end{aligned}
$$

By linearizing the four relevant first order conditions, we obtain the following four Home and Foreign Phillips curves for both the Home and Foreign market:

$$
\begin{aligned}
& \Delta p_{h, t}=\beta \mathrm{E}_{t} \Delta p_{h, t+1}+\frac{\lambda-1}{\alpha_{p}}\left(w_{t}-p_{t}-a_{t}+p_{t}-p_{h, t}\right) \\
& \Delta p_{f, t}=\beta \mathrm{E}_{t} \Delta p_{f, t+1}+\frac{\lambda-1}{\alpha_{p}}\left(w_{t}^{*}-p_{t}^{*}-a_{t}^{*}+p_{t}^{*}-\left(p_{f, t}-s_{t}\right)\right) \\
& \Delta p_{h, t}^{*}=\beta \mathrm{E}_{t} \Delta p_{h, t+1}^{*}+\frac{\lambda-1}{\alpha_{p}}\left(w_{t}-p_{t}-a_{t}+p_{t}-\left(p_{h, t}^{*}+s_{t}\right)\right) \\
& \Delta p_{f, t}^{*}=\beta \mathrm{E}_{t} \Delta p_{f, t+1}^{*}+\frac{\lambda-1}{\alpha_{p}}\left(w_{t}^{*}-p_{t}^{*}-a_{t}^{*}+p_{t}^{*}-p_{f, t}^{*}\right)
\end{aligned}
$$

Endogenous Interest Rate Setting To evaluate the model with a more realistic description of monetary policy, we introduce the following interest rate rule:

$$
i_{t}=\gamma i_{t-1}+(1-\gamma)\left[\phi_{p} \Delta p_{t}+\phi_{y}\left(y_{t}-y_{t}^{\text {Flex }}\right)+\frac{1}{2} \phi_{s} \Delta s_{t}+\nu_{3, t}+\nu_{4, t}\right] \text {. }
$$

Here, $\left(y_{t}-y_{t}^{\text {Flex }}\right)$ is the output gap, defined as log difference between sticky and flexible price output. This is a standard Taylor rule with interest rate and exchange rate smoothing (i.e., the possibility to move the interest rate gradually and to lean against the wind with respect to exchange rate changes). The parameter $\gamma$ is the interest rate smoothing parameter, which will play an important role in our quantitative results. The parameter $\phi_{s}$ is the exchange rate smoothing parameter, that interacts with $\gamma$. We allow for a possible monetary policy response to the exchange rate because this

\footnotetext{
${ }^{30}$ Note that a Home firm can set the price for the Home market without considering the production for the Foreign market because of its linear production technology.
} 
could be welfare enhancing with news shocks as Devereux and Engel (2006) explained. The coefficient on inflation is $\phi_{p}$, and the coefficient on the output gap is $\phi_{y}$.

Calibration We calibrate the model at quarterly frequency, and the preference parameters are standard. The coefficient of relative risk aversion is $\rho=3$. The elasticity of substitution between Home goods and Foreign goods is $\omega=3$. The inverse of labor supply elasticity with respect to the wage is $\psi=0.1$. The rate of time preference is $\beta=0.95$ on an annual basis, while the average duration of price change is one year. The assumed labor share in the economy is $\zeta=2 / 3$, which implies a high markup, but it is still within the norms used in the literature (Also, this markup is used only to determine the labor share). The coefficients of the interest rate rule are $\phi_{p}=1.5$ and $\phi_{y}=1$, in line with a standard Taylor rule specification. ${ }^{31}$ The assumed structure of exogenous shocks is similar to that in the simple model, with only one current shock and one news shock, and is described in appendix.

Under symmetric monetary policy, interest rates responds to relative productivity shocks when $\phi_{y} \neq 0 .{ }^{32}$ This is because the relative output gap is a function of relative productivity. To see this, first notice that the output gap,

$$
y_{t}^{R}-y_{t}^{\text {Flex }, R}=l_{t}^{R}+a_{t}^{R}-\left(l_{t}^{\text {Flex }, R}+a_{t}^{R}\right)
$$

is exactly the same as the relative labor gap. Because relative labor supply depends only on the terms of trade, which in turn depends on productivity, it is evident that the output gap depends only on productivity. ${ }^{33}$

\section{B. Impulse Responses}

In this subsection we discuss selected impulse response functions to current and news shocks to both productivity and monetary policy that describe the propagation mechanism in the extended model. Figures 1 and 2 report the impulse responses of changes in the exchange rate $\left(\Delta s_{t}\right)$, the relative nominal interest rate $\left(i_{t}^{R}\right)$, and the relative nominal return on equity measured in firm local currency $\left(r_{t}^{R}\right)$ under alternative parameter assumptions. Figure 3 reports the impulse responses of the exchange rate, the Home equity return, and the Home interest rate to Home shocks.

Specifically, Figure 1 reports responses to relative current and news productivity and policy shocks, assuming no interest rate smoothing, no exchange rate smoothing, and no persistence in the productivity process. Consider current productivity shocks. A positive current productivity shock induces a negative output gap because the flexible price output increases, while the sticky price output takes time to respond. This negative output gap in turn lowers the interest rate if $\phi_{y}>0$. As interest rates are lower, the exchange rate depreciates $(\Delta s>0)$. Since the current productivity shock

\footnotetext{
${ }^{31} \mathrm{We}$ set $\phi_{y}$ relatively high (equal to one as in an annualized interest rate setting rule) to illustrate the interest rate responses that would otherwise be negligible.

${ }^{32}$ In order to maintain full symmetry, we assume Foreign reacts to exchange rate in a following way: $i_{t}^{*}=\cdots-\phi_{s} \frac{1}{2} \Delta s_{t} \cdots$.

${ }^{33}$ Groen and Matsumoto(2004) show how the terms of trade can be expressed as a function of relative productivity in a similar setup.
} 
increases the revenue of Home firms, the relative return on Home equity increases as well. As a result, the covariance between $\Delta s$ and $r$ tends to be positive in this case.

In contrast, with productivity news shocks, interest rates barely react on impact, because the domestic good price starts to fall on impact given future higher productivity. Demand and actual output increase and the output gap becomes positive as the flexible price output has remained unchanged on impact. The nominal exchange rate depreciates enough to induce a future appreciation of the real exchange rate, consistent with a negative future interest rate differential, associated in turn with a future productivity improvement and negative output gap. As in the case of a current productivity shock, a positive future productivity differential increases future profit, and the relative equity return increases. With both current and news shocks to productivity, the relative return on equity in firm currency $\left(r_{t}^{R}\right)$ reacts more than the exchange rate $\left(\Delta s_{t}\right)$ and it is positively correlated with $\Delta s_{t}$, because $r_{t+1}^{R}=r_{t+1}^{R \$}+\Delta s_{t}$.

The relative magnitude of the response of exchange rate and relative equity returns in firm currency depends on the monetary policy reaction to productivity shocks. If $\phi_{y}=0$, that is, if monetary policy does not react to the relative productivity shock through the output gap, then there is no reaction of the exchange rate to current relative productivity shocks as relative productivity does not affect relative inflation. In this case, the relative equity return in firm local currency is clearly more volatile than the exchange rate, as $\operatorname{Var} r_{t+1}^{R}=\operatorname{Var}\left(r_{t+1}^{R \$}\right)+\operatorname{Var}\left(\Delta s_{t}^{R}\right)$. Notice however that, in expectation, changes in the exchange rate and the relative returns on the equity in local currency are the same as the interest rate differential-i.e., $\mathrm{E}_{t} r_{t+1}^{R}=\mathrm{E}_{t} \Delta s_{t+1}^{R}=i_{t}^{R}$. Hence, after period one, both variables follow the interest rate differential with a lag of one period. If $\phi_{y}>0, \operatorname{Cov}\left(r_{t+1}^{R \$}, \Delta s_{t+1}\right)>0$. Then, from equation (44), we know that $\operatorname{Var}\left(r_{t+1}^{R}\right)>\operatorname{Var}\left(\Delta s_{t}^{R}\right)$. On the other hand, if $\phi_{y}<0$, the sign of this covariance becomes ambiguous. Moreover even if the sign were negative, it remains ambiguous whether the relative equity return is more volatile than the exchange rate return, depending crucially on the variance ratio between productivity and interest rates.

Consider now policy shocks. In response to current monetary policy shocks, the relative return on equity in firm currency is the same as the exchange rate change because $r_{t+1}^{R \$}=0$ without productivity shocks. While current policy shocks induce a large interest differential and an exchange rate appreciation, monetary policy news shocks induce an appreciation and a small negative interest differential. This is because the exchange rate appreciates on the news, which in turn induces lower Home inflation (relative to Foreign), before the actual policy change, which in turn leads to a monetary policy easing through the Taylor rule.

Figure 2 illustrates the consequences of interest rate smoothing and persistent productivity shocks by setting values of the autoregressive parameters for the interest rate and the relative productivity at $\gamma=0.6$ and $\theta^{R}=0.7$, respectively. Under these assumptions, current shocks also provide information about the entire future path, and not only one period ahead like in our simpler model in section 3. As we can see, the interest rate differential becomes much less volatile with smoothing. On the other hand, the exchange rate and the relative equity return are much more volatile because there is more information about the future that is being taken into account on impact.

Finally, Figure 3 illustrates the impact of Home shocks on the Home interest rate and the Home equity return as it is also useful to look at Home variables in addition to relative variables. We assume interest rate smoothing as in the previous experiment and add a small exchange rate smoothing coefficient. So the policy parameters are $\phi_{p}=1.5, \phi_{y}=0.2, \phi_{s}=0.1$ and $\gamma=0.6$. We also set a higher autoregressive coefficient for world productivity (at $\theta^{W}=0.95$ ) than on relative productivity 
$\left(\theta^{R}=0.7\right)$. Under these assumptions, it is easy to see that equity return tends to be more volatile than the exchange rate, as the exchange rate does not depend on world shocks, while Home variables do. On the other hand, the Home interest rate, which is affected by world shocks, is still less volatile than the exchange rate.

\section{Model Evaluation}

We evaluate the model by comparing simulated and data-based second moments for the UK, Japan (JP), and Germany (BD) relative to the U.S., the main floating currencies from 1973 to date, and several model specifications, reported in Table $1 .{ }^{34}$ On the comovement between exchange rate and equity returns, we report statistics for all countries for which we have good equity return data in Table 2.

For the interest rate data, we report both conditional and unconditional standard deviations, with the former computed by running simple univariate autoregressive regressions. In the model, in fact, interest rates should have a significant predictable component. For other asset prices, we report only unconditional standard deviations and correlations, as equity and exchange rate returns have very small predictable components in the data. From the model, we report both conditional and unconditional standard deviations to show that there is little difference between them. We benchmark model-based moments so that the conditional standard deviation of the (quarterly) relative interest rate is about 0.16 percent, as in the data, by scaling the variance covariance matrix of the underlying stochastic processes. Persistence and volatility parameters are the same as in the baseline calibration discussed above unless otherwise noted. We consider interest rate shocks attached to the interest rate rule that are minimal by assuming that their variance is one per cent of the variance of productivity shocks.

We report results for six model specifications. Model 1 assumes a bare-bone monetary policy rule with $\phi_{p}=1.5, \phi_{y}=0.2, \phi_{s}=0.1$, and $\gamma=0.0$, without any correlation between news and current shocks. Model 2 adds a correlation between news and current shocks. This indeed increases the volatility of asset prices relative to both the conditional and unconditional volatility of the real relative interest rate. Model 3 adds moderate interest rate smoothing in the policy rule with $\gamma=0.4$. As we can see, its effect is similar to that of news shocks correlated with current shocks. Quantitatively, however, the effect of interest rate smoothing is bigger because it provides information about the entire future path of interest rates, as opposed to the more limited future information content of the news shocks in our model. Model 4 combines interest rate smoothing and correlated shocks, generating higher asset price volatility. Model 5 has no monetary policy response to the output gap, $\phi_{y}=0$, while Model 6 assumes a small negative coefficient, $\phi_{y}=-0.01$, on the output gap.

The ranking of the model-based volatilities is consistent with the data in most cases. The variance of the relative return on equities in firm local currency $\left(r_{t+1}^{R}\right)$ is larger than exchange rate volatility, which in turn is much larger than the relative interest rate volatility. On the other hand, the model misses the relative size of the volatility of the relative return on equities in investor currency $\left(r_{t+1}^{R \$}\right)$, which is much less volatile than in the data. The reason why we do not do well in terms of relative

\footnotetext{
${ }^{34}$ The interest rate data are 3-month LIBOR, and the sample period is 1987Q1- 2007Q4. We use MSCI series (total equity return indices) for equity returns and end-of-period exchange rates against the U.S. dollar for the UK, Japan, and Germany. For equity prices and exchange rates, the sample period is 1973Q1-2007Q4. Some sub-sample results are available in Table 2
} 
equity return in investor currency is that, in the first four model specifications, monetary policy responds to the output gap. If we shut down the monetary policy response to the output gap, as in Model 5, then the volatility of the exchange rate return falls, and the volatility of the equity return in firm currency becomes comparable to that of the relative return in investor currency.

While this is not necessarily realistic, shutting down the monetary policy response to the output gap, also helps in another dimension. If monetary policy accommodates productivity shocks $\left(\phi_{y}>0\right)$, then we have a positive correlation between the exchange rate and the relative equity return in investor currency, while the correlation is zero if $\phi_{y}=0$, and this is closer to the data. In terms of comovement, in fact, in the data, we find a positive correlation between exchange rate return and relative return in firm local currency for Germany, UK, and many other countries, and a negative correlation for Japan and a few other countries, consistent with the findings reported by Hau and Rey (2006). However, in the data, we also find a large negative correlation between relative return in investor currency and exchange rate for all countries we consider, which is surprising but in principle not inconsistent with the model.

Model 6, in fact, assumes a small negative coefficient $\left(\phi_{y}=-0.01\right)$ on the output gap and matches the data in terms of the sign of this correlation. Empirical estimates of this coefficient are typically positive, but this might be partly due to the fact that the output gap is often measured with trend output in these studies, while the results from our model are generated defining potential output as the flexible price output. For instance, Ireland (2003) finds a small negative coefficient estimating a specification in which the output gap is measured in deviation from the steady state of the model. Nonetheless, assuming this coefficient to be negative remains questionable, although the uniqueness of a stable equilibrium is guaranteed as long as its value is sufficiently small.

\section{Conclusions}

In this paper, we study the role of money supply and productivity news shocks for equity price and exchange rate dynamics. We do so in a standard dynamic stochastic general equilibrium (DSGE) open economy model, under complete markets, with alternative information assumptions about the future value of fundamentals and the monetary policy reaction to productivity shocks. We focus on volatility and comovement of equity prices and exchange rates.

We show that if news shocks are positively correlated with current shocks then asset prices become more volatile without affecting the volatility of the underlying fundamental processes. The intuition is that asset prices respond to both current shocks and today's news shocks, while fundamentals evolve according to current shocks and yesterday's news shocks. But yesterday's news shocks can potentially offset today's surprises, while today's surprises and news shocks tend to move in the same direction if positively correlated. In other words, if current and news shocks are positively correlated, news about future fundamentals carries an information content similar to today's surprise, and asset prices can move more in the same direction than the fundamentals. This mechanism explains at least

some of the excess volatility in asset prices relative to the fundamentals that we see in the data. It also provides an explanation of why persistent stochastic processes generate higher asset price volatility.

While our model is too simple to match well all relevant data moments, it captures the ranking of exchange rate, equity price, and interest rate volatility in the data. The model also naturally generates a positive correlation between exchange rate and equity returns in firm local currency as in the data. 
Finally, the model can match the correlation between exchange rate and equity returns in investor currency if we assume a small negative monetary policy reaction to the output gap, albeit at the cost of generating somewhat lower exchange rate volatility. These results suggest that the monetary policy reaction to the output gap has a significant impact on the comovements between exchange rate and equity return. 
Table 1. Model Evaluation

\begin{tabular}{|c|c|c|c|c|c|c|c|c|c|c|}
\hline & & \multicolumn{3}{|c|}{ Data $^{a}$} & \multicolumn{6}{|c|}{ Model } \\
\hline & & UK & JP & $\mathrm{BD}$ & $1^{\mathrm{d}}$ & $2^{\mathrm{e}}$ & $3^{\mathrm{f}}$ & $4^{\mathrm{g}}$ & $5^{\mathrm{h}}$ & $6^{\mathrm{i}}$ \\
\hline \multirow{2}{*}{$\begin{array}{l}\sigma_{t}\left(i_{t}^{R}\right)^{\mathrm{b}} \\
\sigma\left(i_{t}^{R}\right)\end{array}$} & \multirow[t]{2}{*}{ Relative Interest } & 0.16 & 0.14 & 0.15 & 0.16 & 0.16 & 0.16 & 0.16 & 0.16 & 0.16 \\
\hline & & 0.52 & 0.54 & 0.63 & 0.27 & 0.36 & 0.53 & 0.85 & 0.51 & 0.52 \\
\hline \multirow{2}{*}{$\begin{array}{l}\sigma_{t}\left(\Delta s_{t+1}\right) \\
\sigma\left(\Delta s_{t+1}\right)\end{array}$} & \multirow[t]{2}{*}{ Exchange Rate } & & & & 0.69 & 1.10 & 3.11 & 5.26 & 2.05 & 2.12 \\
\hline & & 4.97 & 6.07 & 6.03 & 0.74 & 1.16 & 3.15 & 5.32 & 2.11 & 2.18 \\
\hline \multirow{2}{*}{$\begin{array}{l}\sigma_{t}\left(r_{t+1}^{R}\right) \\
\sigma\left(r_{t+1}^{R}\right)\end{array}$} & Relative Return & & & & 1.15 & 1.83 & 5.51 & 9.35 & 8.73 & 8.22 \\
\hline & in Firm Currency & 7.24 & 9.08 & 8.86 & 1.18 & 1.86 & 5.54 & 9.39 & 8.74 & 8.23 \\
\hline \multirow{2}{*}{$\begin{array}{l}\sigma_{t}\left(r_{t+1}^{R \$}\right) \\
\sigma\left(r_{t+1}^{R \$}\right)\end{array}$} & Relative Return & & & & 0.46 & 0.73 & 2.43 & 4.14 & 8.48 & 8.48 \\
\hline & in Investor Currency & 8.32 & 10.96 & 9.46 & 0.46 & 0.73 & 2.43 & 4.14 & 8.48 & 8.48 \\
\hline \multirow{2}{*}{\multicolumn{2}{|c|}{$\begin{array}{l}\rho_{t}\left(r_{t+1}^{R}, \Delta s_{t+1}\right)^{\mathrm{c}} \\
\rho\left(r_{t+1}^{R}, \Delta s_{t+1}\right)\end{array}$}} & & & & 1.00 & 1.00 & 1.00 & 1.00 & 0.23 & 0.00 \\
\hline & & 0.11 & -0.01 & 0.24 & 0.99 & 0.99 & 0.99 & 0.99 & 0.24 & 0.01 \\
\hline \multirow{2}{*}{\multicolumn{2}{|c|}{$\begin{array}{l}\rho_{t}\left(r_{t+1}^{R \$}, \Delta s_{t+1}\right) \\
\rho\left(r_{t+1}^{R \$}, \Delta s_{t+1}\right)\end{array}$}} & & & & 0.98 & 0.98 & 0.98 & 0.98 & 0.00 & -0.25 \\
\hline & & -0.50 & -0.56 & -0.41 & 0.91 & 0.93 & 0.96 & 0.97 & 0.00 & -0.24 \\
\hline
\end{tabular}

a The variables are relative to the US.

${ }^{\mathrm{b}} \sigma(x)$ and $\sigma_{t}(x)$ are unconditional and conditional standard deviation of variable $x$ respectively.

${ }^{c} \rho(x, y)$ and $\rho_{t}(x, y)$ are unconditional and conditional correlation between variable $x$ and $y$.

${ }^{\mathrm{d}}$ Model 1: Base Model: no correlation between news and current shocks. $\left(\gamma=0, \phi_{y}=0.2, \varrho_{a}=\varrho_{m}=0\right.$.)

e Model 2: Model 1 with correlated shocks $\left(\varrho_{a}=\varrho_{m}=0.9\right.$ for both $R$ and $\left.W\right)$.

${ }^{\mathrm{f}}$ Model 3: Model 1 with interest rate smoothing $(\gamma=0.4)$.

g Model 4: Model 3 with correlated shocks $\left(\varrho_{a}=\varrho_{m}=0.9\right.$ for both $R$ and $W$ ).

${ }^{\mathrm{h}}$ Model 5: Model 4 without monetary policy reaction to output gap $\left(\phi_{y}=0.0\right)$.

i Model 6: Model 4 with negative monetary policy reaction to output gap $\left(\phi_{y}=-0.01\right)$. 
Table 2. Volatility and Comovement of Exchange Rates and Equity Returns ${ }^{\mathrm{a}}$

\begin{tabular}{|c|c|c|c|c|c|c|c|c|}
\hline & & $\begin{array}{r}\text { 1973Q1 } \\
-2007 Q 4\end{array}$ & & $\begin{array}{r}\text { 1973Q1 } \\
-2007 Q 4\end{array}$ & $\begin{array}{r}\text { 1970Q1 } \\
-1979 Q 4\end{array}$ & $\begin{array}{r}\text { 1980Q1 } \\
-1989 Q 4\end{array}$ & $\begin{array}{r}\text { 1990Q1 } \\
-1999 Q 4\end{array}$ & $\begin{array}{r}2000 \mathrm{Q} 1 \\
-2007 \mathrm{Q} 4\end{array}$ \\
\hline Australia & $\begin{array}{c}\sigma\left(r_{t}^{R}\right) \\
\sigma\left(r_{t}^{R \$}\right)\end{array}$ & $\begin{array}{l}7.85 \\
9.42\end{array}$ & $\begin{array}{c}\rho\left(r_{t}^{R}, \Delta S_{t}\right) \\
\rho\left(r_{t}^{R \$}, \Delta S_{t}\right)\end{array}$ & $\begin{array}{l}-0.03 \\
-0.55\end{array}$ & $\begin{array}{l}-0.03 \\
-0.37\end{array}$ & $\begin{array}{l}-0.12 \\
-0.57\end{array}$ & $\begin{array}{l}-0.15 \\
-0.69\end{array}$ & $\begin{array}{r}0.43 \\
-0.60\end{array}$ \\
\hline Austria & $\begin{array}{c}\sigma\left(r_{t}^{R}\right) \\
\sigma\left(r_{t}^{R \$}\right)\end{array}$ & $\begin{array}{l}10.71 \\
11.52\end{array}$ & $\begin{array}{c}\rho\left(r_{t}^{R}, \Delta S_{t}\right) \\
\rho\left(r_{t}^{R \$}, \Delta S_{t}\right)\end{array}$ & $\begin{array}{r}0.14 \\
-0.39\end{array}$ & $\begin{array}{r}0.07 \\
-0.39\end{array}$ & $\begin{array}{l}-0.04 \\
-0.55\end{array}$ & $\begin{array}{r}0.47 \\
-0.04\end{array}$ & $\begin{array}{r}0.19 \\
-0.41\end{array}$ \\
\hline Belgium & $\begin{array}{c}\sigma\left(r_{t}^{R}\right) \\
\sigma\left(r_{t}^{R \$}\right)\end{array}$ & $\begin{array}{l}8.06 \\
9.60\end{array}$ & $\begin{array}{c}\rho\left(r_{t}^{R}, \Delta S_{t}\right) \\
\rho\left(r_{t}^{R \$}, \Delta S_{t}\right)\end{array}$ & $\begin{array}{r}0.11 \\
-0.55\end{array}$ & $\begin{array}{l}-0.08 \\
-0.61\end{array}$ & $\begin{array}{r}0.17 \\
-0.53\end{array}$ & $\begin{array}{r}0.31 \\
-0.53\end{array}$ & $\begin{array}{r}0.00 \\
-0.52\end{array}$ \\
\hline Canada & $\begin{array}{c}\sigma\left(r_{t}^{R}\right) \\
\sigma\left(r_{t}^{R \$}\right)\end{array}$ & $\begin{array}{l}5.48 \\
6.26\end{array}$ & $\begin{array}{c}\rho\left(r_{t}^{R}, \Delta S_{t}\right) \\
\rho\left(r_{t}^{R \$}, \Delta S_{t}\right)\end{array}$ & $\begin{array}{l}-0.07 \\
-0.49\end{array}$ & $\begin{array}{r}0.19 \\
-0.15\end{array}$ & $\begin{array}{l}-0.38 \\
-0.66\end{array}$ & $\begin{array}{l}-0.27 \\
-0.56\end{array}$ & $\begin{array}{r}0.23 \\
-0.51\end{array}$ \\
\hline Denmark & $\begin{array}{c}\sigma\left(r_{t}^{R}\right) \\
\sigma\left(r_{t}^{R \$}\right)\end{array}$ & $\begin{array}{l}8.87 \\
8.72\end{array}$ & $\begin{array}{c}\rho\left(r_{t}^{R}, \Delta S_{t}\right) \\
\rho\left(r_{t}^{R \$}, \Delta S_{t}\right)\end{array}$ & $\begin{array}{r}0.35 \\
-0.30\end{array}$ & $\begin{array}{r}0.06 \\
-0.32\end{array}$ & $\begin{array}{r}0.30 \\
-0.33\end{array}$ & $\begin{array}{r}0.43 \\
-0.27\end{array}$ & $\begin{array}{r}0.68 \\
-0.20\end{array}$ \\
\hline France & $\begin{array}{c}\sigma\left(r_{t}^{R}\right) \\
\sigma\left(r_{t}^{R \$}\right)\end{array}$ & $\begin{array}{l}8.55 \\
9.95\end{array}$ & $\begin{array}{c}\rho\left(r_{t}^{R}, \Delta S_{t}\right) \\
\rho\left(r_{t}^{R \$}, \Delta S_{t}\right)\end{array}$ & $\begin{array}{r}0.08 \\
-0.52\end{array}$ & $\begin{array}{l}-0.32 \\
-0.64\end{array}$ & $\begin{array}{l}-0.03 \\
-0.57\end{array}$ & $\begin{array}{r}0.53 \\
-0.28\end{array}$ & $\begin{array}{r}0.31 \\
-0.58\end{array}$ \\
\hline Germany & $\begin{array}{c}\sigma\left(r_{t}^{R}\right) \\
\sigma\left(r_{t}^{R \$}\right)\end{array}$ & $\begin{array}{l}8.86 \\
9.46\end{array}$ & $\begin{array}{c}\rho\left(r_{t}^{R}, \Delta S_{t}\right) \\
\rho\left(r_{t}^{R \$}, \Delta S_{t}\right)\end{array}$ & $\begin{array}{r}0.24 \\
-0.41\end{array}$ & $\begin{array}{r}0.09 \\
-0.44\end{array}$ & $\begin{array}{r}0.12 \\
-0.53\end{array}$ & $\begin{array}{r}0.52 \\
-0.16\end{array}$ & $\begin{array}{r}0.18 \\
-0.41\end{array}$ \\
\hline Hong Kong & $\begin{array}{c}\sigma\left(r_{t}^{R}\right) \\
\sigma\left(r_{t}^{R \$}\right)\end{array}$ & $\begin{array}{l}15.71 \\
16.55\end{array}$ & $\begin{array}{c}\rho\left(r_{t}^{R}, \Delta S_{t}\right) \\
\rho\left(r_{t}^{R \$}, \Delta S_{t}\right)\end{array}$ & $\begin{array}{l}-0.30 \\
-0.43\end{array}$ & $\begin{array}{l}-0.17 \\
-0.26\end{array}$ & $\begin{array}{l}-0.42 \\
-0.57\end{array}$ & $\begin{array}{l}-0.22 \\
-0.24\end{array}$ & $\begin{array}{l}-0.46 \\
-0.48\end{array}$ \\
\hline Italy & $\begin{array}{c}\sigma\left(r_{t}^{R}\right) \\
\sigma\left(r_{t}^{R \$}\right)\end{array}$ & $\begin{array}{l}11.38 \\
12.32\end{array}$ & $\begin{array}{c}\rho\left(r_{t}^{R}, \Delta S_{t}\right) \\
\rho\left(r_{t}^{R \$}, \Delta S_{t}\right)\end{array}$ & $\begin{array}{r}0.07 \\
-0.39\end{array}$ & $\begin{array}{l}-0.16 \\
-0.43\end{array}$ & $\begin{array}{r}0.09 \\
-0.36\end{array}$ & $\begin{array}{r}0.30 \\
-0.26\end{array}$ & $\begin{array}{r}0.05 \\
-0.74\end{array}$ \\
\hline Japan & $\begin{array}{c}\sigma\left(r_{t}^{R}\right) \\
\sigma\left(r_{t}^{R \$}\right)\end{array}$ & $\begin{array}{r}9.08 \\
10.96\end{array}$ & $\begin{array}{c}\rho\left(r_{t}^{R}, \Delta S_{t}\right) \\
\rho\left(r_{t}^{R \$}, \Delta S_{t}\right)\end{array}$ & $\begin{array}{l}-0.01 \\
-0.56\end{array}$ & $\begin{array}{r}0.02 \\
-0.42\end{array}$ & $\begin{array}{l}-0.10 \\
-0.68\end{array}$ & $\begin{array}{r}0.01 \\
-0.55\end{array}$ & $\begin{array}{r}0.15 \\
-0.42\end{array}$ \\
\hline Netherlands & $\begin{array}{c}\sigma\left(r_{t}^{R}\right) \\
\sigma\left(r_{t}^{R \Phi}\right)\end{array}$ & $\begin{array}{l}6.15 \\
6.87\end{array}$ & $\begin{array}{c}\rho\left(r_{t}^{R}, \Delta S_{t}\right) \\
\rho\left(r_{t}^{R \$}, \Delta S_{t}\right)\end{array}$ & $\begin{array}{r}0.35 \\
-0.55\end{array}$ & $\begin{array}{r}0.18 \\
-0.39\end{array}$ & $\begin{array}{r}0.34 \\
-0.68\end{array}$ & $\begin{array}{r}0.56 \\
-0.49\end{array}$ & $\begin{array}{r}0.32 \\
-0.45\end{array}$ \\
\hline Norway & $\begin{array}{c}\sigma\left(r_{t}^{R}\right) \\
\sigma\left(r_{t}^{R \Phi}\right)\end{array}$ & $\begin{array}{l}12.46 \\
13.49\end{array}$ & $\begin{array}{c}\rho\left(r_{t}^{R}, \Delta S_{t}\right) \\
\rho\left(r_{t}^{R \$}, \Delta S_{t}\right)\end{array}$ & $\begin{array}{r}0.00 \\
-0.38\end{array}$ & $\begin{array}{l}-0.13 \\
-0.38\end{array}$ & $\begin{array}{l}-0.17 \\
-0.49\end{array}$ & $\begin{array}{r}0.34 \\
-0.14\end{array}$ & $\begin{array}{r}0.19 \\
-0.48\end{array}$ \\
\hline Singapore & $\begin{array}{c}\sigma\left(r_{t}^{R}\right) \\
\sigma\left(r_{t}^{R \$}\right)\end{array}$ & $\begin{array}{l}11.77 \\
12.30\end{array}$ & $\begin{array}{c}\rho\left(r_{t}^{R}, \Delta S_{t}\right) \\
\rho\left(r_{t}^{R \$}, \Delta S_{t}\right)\end{array}$ & $\begin{array}{l}-0.07 \\
-0.30\end{array}$ & $\begin{array}{l}-0.06 \\
-0.25\end{array}$ & $\begin{array}{r}0.00 \\
-0.18\end{array}$ & $\begin{array}{l}-0.07 \\
-0.31\end{array}$ & $\begin{array}{l}-0.03 \\
-0.32\end{array}$ \\
\hline Spain & $\begin{array}{c}\sigma\left(r_{t}^{R}\right) \\
\sigma\left(r_{t}^{R \$}\right)\end{array}$ & $\begin{array}{l}10.26 \\
11.33\end{array}$ & $\begin{array}{c}\rho\left(r_{t}^{R}, \Delta S_{t}\right) \\
\rho\left(r_{t}^{R \$}, \Delta S_{t}\right)\end{array}$ & $\begin{array}{r}0.07 \\
-0.43\end{array}$ & $\begin{array}{l}-0.44 \\
-0.69\end{array}$ & $\begin{array}{r}0.02 \\
-0.44\end{array}$ & $\begin{array}{r}0.50 \\
-0.07\end{array}$ & $\begin{array}{r}0.24 \\
-0.59\end{array}$ \\
\hline Sweden & $\begin{array}{c}\sigma\left(r_{t}^{R}\right) \\
\sigma\left(r_{t}^{R \$}\right)\end{array}$ & $\begin{array}{r}10.30 \\
9.55\end{array}$ & $\begin{array}{c}\rho\left(r_{t}^{R}, \Delta S_{t}\right) \\
\rho\left(r_{t}^{R \$}, \Delta S_{t}\right)\end{array}$ & $\begin{array}{r}0.40 \\
-0.16\end{array}$ & $\begin{array}{r}0.17 \\
-0.26\end{array}$ & $\begin{array}{r}0.35 \\
-0.21\end{array}$ & $\begin{array}{l}0.63 \\
0.12\end{array}$ & $\begin{array}{r}0.13 \\
-0.50\end{array}$ \\
\hline Switzerland & $\begin{array}{c}\sigma\left(r_{t}^{R}\right) \\
\sigma\left(r_{t}^{R \$}\right)\end{array}$ & $\begin{array}{l}6.78 \\
8.07\end{array}$ & $\begin{array}{c}\rho\left(r_{t}^{R}, \Delta S_{t}\right) \\
\rho\left(r_{t}^{R \$}, \Delta S_{t}\right)\end{array}$ & $\begin{array}{r}0.28 \\
-0.59\end{array}$ & $\begin{array}{r}0.19 \\
-0.55\end{array}$ & $\begin{array}{r}0.17 \\
-0.68\end{array}$ & $\begin{array}{r}0.52 \\
-0.41\end{array}$ & $\begin{array}{r}0.13 \\
-0.62\end{array}$ \\
\hline UK & $\begin{array}{l}\sigma\left(r_{t}^{R}\right) \\
\sigma\left(r_{t}^{R \$}\right)\end{array}$ & $\begin{array}{l}7.24 \\
8.32\end{array}$ & $\begin{array}{c}\rho\left(r_{t}^{R}, \Delta S_{t}\right) \\
\rho\left(r_{t}^{R \$}, \Delta S_{t}\right)\end{array}$ & $\begin{array}{r}0.11 \\
-0.50\end{array}$ & $\begin{array}{l}-0.12 \\
-0.43\end{array}$ & $\begin{array}{r}0.20 \\
-0.64\end{array}$ & $\begin{array}{r}0.33 \\
-0.61\end{array}$ & $\begin{array}{r}0.27 \\
-0.59\end{array}$ \\
\hline
\end{tabular}

${ }^{\text {a }}$ Quarterly MSCI total return index relative to US. 

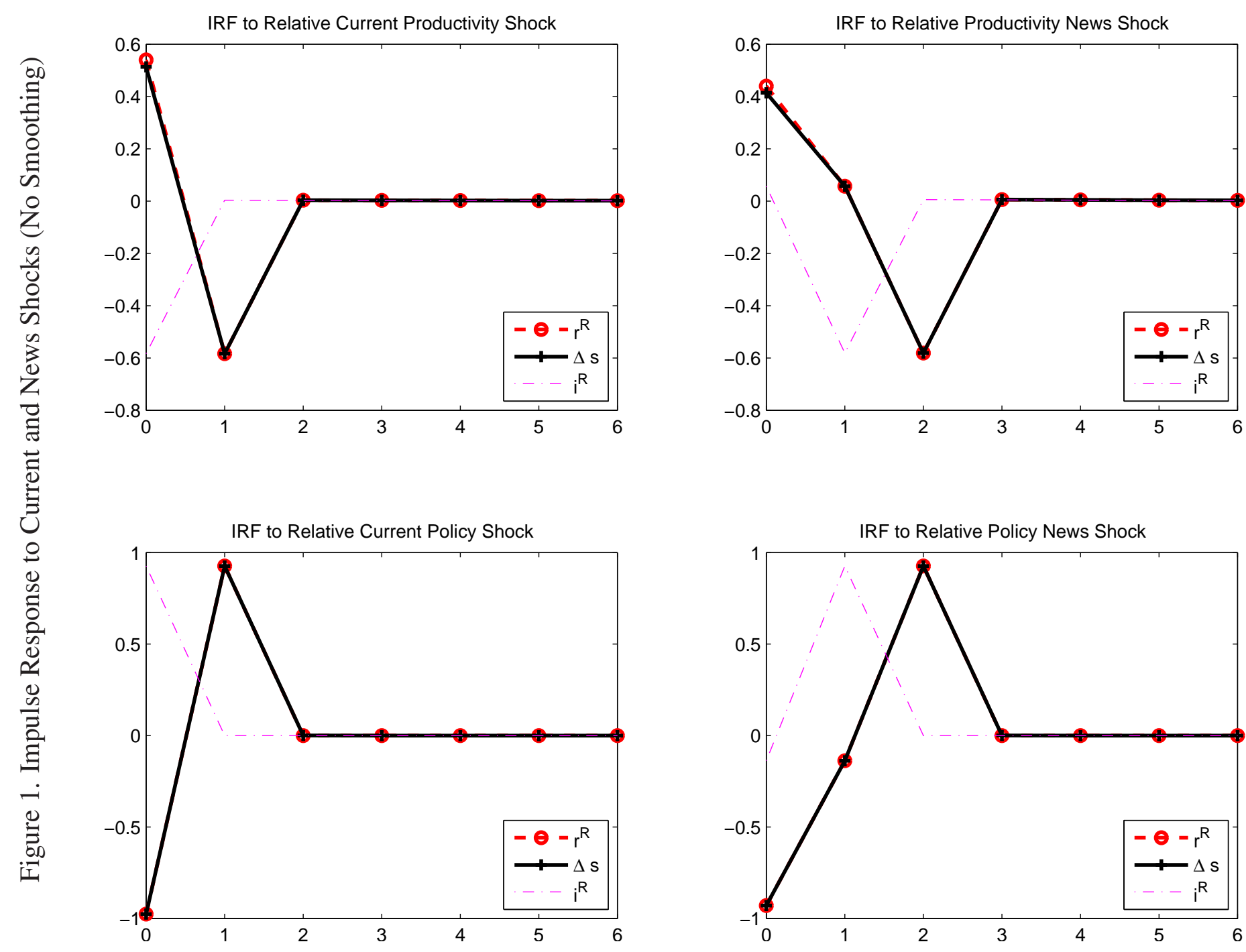

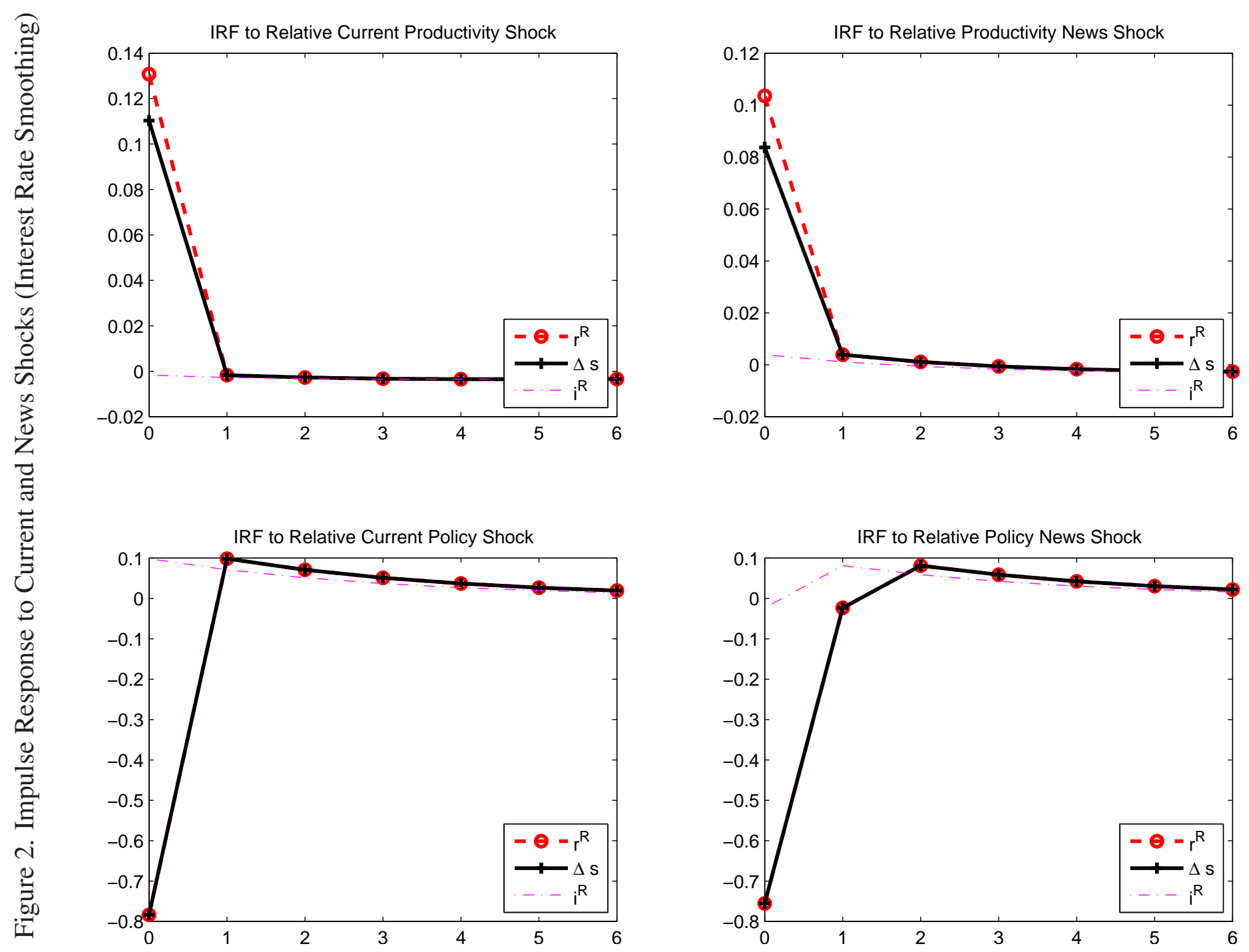

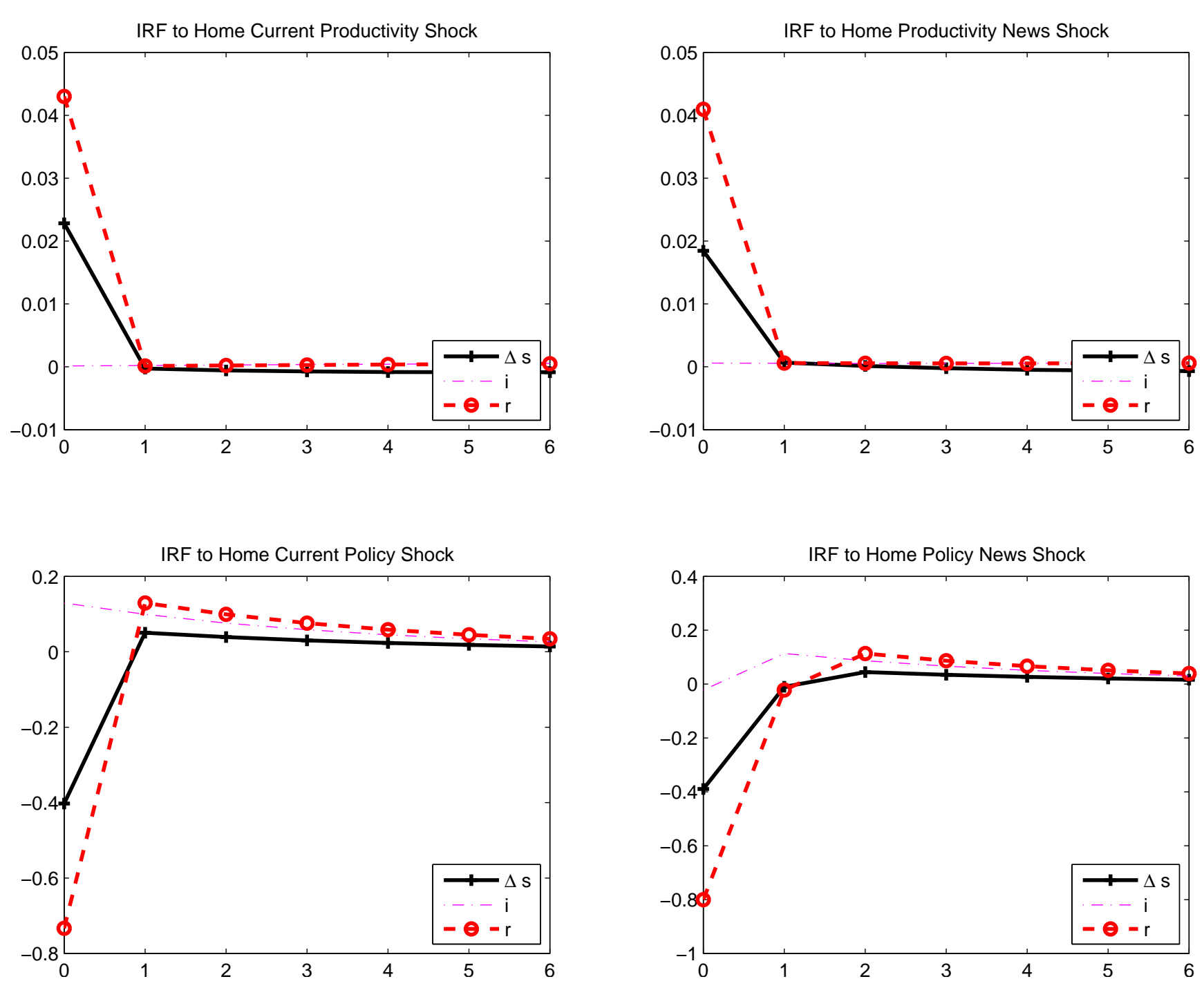
In this appendix we report the complete solution of the model described in section 2 and extended in section $4 .{ }^{35}$

\section{A. Notation}

We denote the log deviation of any variables from the initial symmetric steady state with lower case letters. That is

$$
z_{t} \equiv \ln \left(Z_{t}\right)-\ln \left(Z_{0}\right)
$$

We also use an asterisk $*$ to denote foreign variables, superscript $R$ for relative variables, and superscript $W$ for world average, i.e.,

$$
\begin{aligned}
z_{t}^{R} & \equiv z_{t}-z_{t}^{*} \\
z_{t}^{W} & \equiv \frac{1}{2} z_{t}+\frac{1}{2} z_{t}^{*}
\end{aligned}
$$

\section{B. Model Equilibrium Conditions}

The log-linear version of the model can be summarized by the following equations and their foreign counterparts:

$$
\begin{aligned}
\varepsilon\left(m_{t}-p_{t}\right) & =\rho c_{t}+\frac{\beta}{1-\beta} \mathrm{E}_{t} d_{t, t+1} \\
d_{t, t+s} & =\rho c_{t}+p_{t}-\rho c_{t+s}-p_{t+s} \\
i_{t} & =-\mathrm{E}_{t} d_{t, t+1} \\
w_{t} & =\psi l_{t}+\rho c_{t}+p_{t} \\
p_{t} & =\frac{1}{2} p_{h, t}+\frac{1}{2} p_{f, t} \\
p_{h, t} & =\mathrm{E}_{t-1}\left(w_{t}-a_{t}\right) \\
p_{f, t} & =\mathrm{E}_{t-1}\left(w_{t}^{*}-a_{t}^{*}+s_{t}\right) \\
a_{t}+l_{t} & =\frac{1}{2}\left[-\omega\left(p_{h, t}-p_{t}\right)+c_{t}\right]+\frac{1}{2}\left[-\omega\left(p_{h, t}^{*}-p_{t}^{*}\right)+c_{t}^{*}\right] \\
\rho\left(c_{t}-c_{t}^{*}\right) & =s_{t}+p_{t}^{*}-p_{t} \\
\tau_{t} & \equiv p_{h, t}-p_{f, t}=p_{h, t}^{*}-p_{f, t}^{*}
\end{aligned}
$$

Home pre-dividend equity price and the equity return are, respectively:

$$
\begin{aligned}
& q_{t}=(1-\beta) \sum_{s=0}^{\infty} \mathrm{E}_{t} \beta^{s}\left(d_{t, t+s}+\pi_{t+s}\right), \\
& r_{t+1}=q_{t+1}-\frac{1}{\beta} q_{t}+\frac{1-\beta}{\beta} \pi_{t} .
\end{aligned}
$$

\footnotetext{
${ }^{35}$ The derivations are available form the authors on request.
} 


\section{Model Solution}

Using the assumptions on the underlying shocks, the solution for relative variables is given by the following equations:

$$
\begin{aligned}
s_{t}= & \mathrm{E}_{t-1} m_{t}^{R}+(1-\beta) \varepsilon\left(m_{t}^{R}-\mathrm{E}_{t-1} m_{t}^{R}\right)+\beta\left(\mathrm{E}_{t} m_{t+1}^{R}-\mathrm{E}_{t-1} m_{t}^{R}\right) \\
p_{t}^{R}= & \mathrm{E}_{t-1} m_{t}^{R} \\
\rho c_{t}^{R}= & (1-\beta) \varepsilon\left(m_{t}^{R}-\mathrm{E}_{t-1} m_{t}^{R}\right)+\beta\left(\mathrm{E}_{t} m_{t+1}^{R}-\mathrm{E}_{t-1} m_{t}^{R}\right) \\
\tau_{t}= & -\frac{\psi+1}{\omega \psi+1} \mathrm{E}_{t-1} a_{t}^{R} \\
l_{t}^{R}= & \omega\left(\frac{\psi+1}{\omega \psi+1}\right) \mathrm{E}_{t-1} a_{t}^{R}-a_{t}^{R} \\
w_{t}^{R}= & \psi\left[\omega\left(\frac{\psi+1}{\omega \psi+1}\right) \mathrm{E}_{t-1} a_{t}^{R}-a_{t}^{R}\right] \\
& +\mathrm{E}_{t-1} m_{t}^{R}+(1-\beta) \varepsilon\left(m_{t}^{R}-\mathrm{E}_{t-1} m_{t}^{R}\right)+\beta\left(\mathrm{E}_{t} m_{t+1}^{R}-\mathrm{E}_{t-1} m_{t}^{R}\right) \\
q_{t}^{R}= & s_{t}+(1-\beta)(\psi+1)\left[\frac{\omega-1}{\omega \psi+1}\left(\frac{1}{1-\beta \theta} a_{t}^{R}-\nu_{1, t}^{R}+\frac{\beta}{1-\beta \theta} \nu_{2, t}^{R}\right)+\frac{\zeta}{1-\zeta} \nu_{1, t}^{R}\right] \\
\pi_{t}^{R}= & s_{t}+(\psi+1)\left[\frac{\omega-1}{\omega \psi+1}\left(a_{t}^{R}-\nu_{1, t}^{R}\right)+\frac{\zeta}{1-\zeta} \nu_{1, t}^{R}\right] \\
r_{t}^{R}= & \Delta s_{t+1} \\
& +(1-\beta)(\psi+1)\left[\left(\frac{\omega-1}{\omega \psi+1} \frac{\beta \theta}{1-\beta \theta}+\frac{\zeta}{1-\zeta}\right) \nu_{1, t+1}^{R}+\frac{\omega-1}{\omega \psi+1} \frac{\beta}{1-\beta \theta} \nu_{2, t+1}^{R}\right]
\end{aligned}
$$

where $\zeta \equiv \frac{\lambda-1}{\lambda}$ is labor share of the economy.

For world variables, we have

$$
\begin{aligned}
p_{t}^{W}= & -\mathrm{E}_{t-1} \frac{\rho}{\varepsilon} \frac{\psi+1}{\rho+\psi} a_{t}^{W}+\mathrm{E}_{t-1} m_{t}^{W} \\
c_{t}^{W}= & \frac{1}{\rho}\left[(1-\beta) \varepsilon\left(\mu_{1, t}^{W}\right)+\beta\left(\mu_{1, t}^{W}+\mu_{2, t}^{W}\right)\right] \\
& +\frac{\psi+1}{\rho+\psi}\left[\mathrm{E}_{t-1} a_{t}^{W}+\beta\left(1-\frac{1}{\varepsilon}\right)\left(\nu_{1, t}^{W}+\nu_{2, t}^{W}\right)\right] \\
l_{t}^{W}= & c_{t}^{W}-a_{t}^{W} \\
w_{t}^{W}= & \psi l_{t}^{W}+\rho c_{t}^{W}+p_{t}^{W} \\
\pi_{t}^{W}= & p_{t}^{W}+c_{t}^{W}+\frac{\zeta}{1-\zeta}\left[(\psi+1)\left(a_{t}^{W}-\mathrm{E}_{t-1} a_{t}^{W}\right)-(\rho+\psi)\left(c_{t}^{W}-\mathrm{E}_{t-1} c_{t}^{W}\right)\right] \\
q_{t}^{W}= & (1-\rho) \beta\left(\mathrm{E}_{t} c_{t+1}^{W}-c_{t}^{W}\right)+c_{t}^{W}+p_{t}^{W}+(1-\beta) \frac{\zeta}{1-\zeta}\left[(\psi+1) a_{t}^{W}-(\rho+\psi) c_{t}^{W}\right] \\
r_{t+1}^{W}= & \Delta p_{t+1}^{W}+\rho\left(\mathrm{E}_{t} c_{t+1}^{W}-c_{t}^{W}\right) \\
& +\beta(1-\rho)\left(\mathrm{E}_{t+1} c_{t+2}^{W}-\mathrm{E}_{t} c_{t+1}^{W}\right)+[\rho+(1-\beta)(1-\rho)]\left(c_{t+1}^{W}-\mathrm{E}_{t} c_{t+1}^{W}\right) \\
& +(1-\beta) \frac{\zeta}{1-\zeta}\left[(\psi+1)\left(a_{t+1}^{W}-\mathrm{E}_{t} a_{t+1}^{W}\right)-(\rho+\psi)\left(c_{t+1}^{W}-\mathrm{E}_{t} c_{t+1}^{W}\right)\right] .
\end{aligned}
$$




\section{Extended Model Equilibrium Conditions}

The equilibrium conditions for the extended model with staggered price adjustments and rule-based interest rate setting are as follows:

$$
\begin{aligned}
& \mathrm{E}_{t}\left(\rho c_{t+1}^{W}\right)=i_{t}^{W}-\mathrm{E}_{t}\left(\Delta p_{t+1}^{W}\right)+\rho c_{t}^{W} \\
& \mathrm{E}_{t}\left(\Delta s_{t+1}\right)=i_{t}^{R} \\
& \Delta p_{t}^{R}=\beta \mathrm{E}_{t} \Delta p_{t+1}^{R}+\frac{\lambda-1}{\alpha_{p}} \rho c_{t}^{R} \\
& \Delta p_{t}^{W}=\beta \mathrm{E}_{t} \Delta p_{t+1}^{W}+\frac{\lambda-1}{\alpha_{p}}\left(\tilde{w}_{t}^{W}-a_{t}^{W}\right) \\
& \Delta \tau_{t}=\beta \mathrm{E}_{t} \Delta \tau_{t+1}+\frac{\lambda-1}{\alpha_{p}}\left(\tilde{w}_{t}^{R}-a_{t}^{R}-\tau_{t}-\rho c_{t}^{R}\right) \\
& \tilde{q}_{t}^{R}=\beta \mathrm{E}_{t} \tilde{q}_{t+1}^{R}+(1-\beta) \tilde{\pi}_{t}^{R}-\beta \mathrm{E}_{t}\left(\Delta s_{t+1}-\Delta p_{t+1}^{R}\right) \\
& \tilde{q}_{t}^{W}=\beta \mathrm{E}_{t} \tilde{q}_{t+1}^{W}+(1-\beta) \tilde{\pi}_{t}^{W}+\beta \rho c_{t}^{W}-\beta \mathrm{E}_{t}\left(\rho c_{t+1}^{W}\right) \\
& \rho c_{t}^{R}=\rho c_{t-1}^{R}+\Delta s_{t}-\Delta p_{t}^{R} \\
& \tilde{w}_{t}^{R}=\psi l_{t}^{R}+\rho c_{t}^{R} \\
& \tilde{w}_{t}^{W}=\psi l_{t}^{W}+\rho c_{t}^{W} \\
& l_{t}^{R}=-\omega \tau_{t}-a_{t}^{R} \\
& l_{t}^{W}=c_{t}^{W}-a_{t}^{W} \\
& (1-\zeta) \tilde{\pi}_{t}^{R}=(1-\omega) \tau_{t}+\rho c_{t}^{R}-\zeta\left(\tilde{w}_{t}^{R}+l_{t}^{R}\right) \\
& (1-\zeta) \tilde{\pi}_{t}^{W}=c_{t}^{W}-\zeta\left(\tilde{w}_{t}^{W}+l_{t}^{W}\right) \\
& l_{t}^{\text {Flex }, R}=\frac{\omega-1}{\omega \psi+1} a_{t}^{R} \text {. } \\
& l_{t}^{\text {Flex }, W}=\frac{1-\rho}{\psi+\rho} a_{t}^{W} \\
& i_{t}^{R}=\gamma i_{t-1}^{R}+(1-\gamma)\left[\phi_{p} \Delta p_{t}^{R}+\phi_{y}\left(l_{t}^{R}-l_{t}^{\text {Flex }, R}\right)+\phi_{s} \Delta s_{t}+\nu_{3, t}^{R}+\nu_{4, t-1}^{R}\right] \\
& i_{t}^{W}=\gamma i_{t-1}^{W}+(1-\gamma)\left[\phi_{p} \Delta p_{t}^{W}+\phi_{y}\left(l_{t}^{W}-l_{t}^{\text {Flex }, W}\right)+\nu_{3, t}^{W}+\nu_{4, t-1}^{W}\right] \\
& a_{t}^{R}=\theta^{R} a_{t-1}^{R}+\left(1-\theta^{R}\right)\left(\nu_{1, t}^{R}+\nu_{2, t-1}^{R}\right) \\
& a_{t}^{W}=\theta^{W} a_{t-1}^{W}+\left(1-\theta^{W}\right)\left(\nu_{1, t}^{W}+\nu_{2, t-1}^{W}\right)
\end{aligned}
$$




\section{REFERENCES}

Andersen, Torben G. , Tim Bollerslev, Francis X. Diebold, and Clara Vega 2007 "Real-Time Price Discovery in Stock, Bond and Foreign Exchange Markets," Journal of International Economics, Vol. 73 (2), 251-277.

Backus, David K, Kehoe, Patrick J and Kydland, Finn E, 1992. "International Real Business Cycles," Journal of Political Economy, University of Chicago Press, Vol. 100 (4), 745-75, August.

Beaudry, Paul and Franck Portier, 2006. "Stock Prices, News, and Economic Fluctuations," American Economic Review, Vol. 96 (4), 1293-1307.

Benigno, Gianluca, 2004, "Real Exchange Rate Persistence and Monetary Policy Rules" Journal of Monetary Economics, Vol. 51, 473-502

Blinder, Alan S., Michael Ehrmann, Marcel Fratzscher, Jakob De Haan, David-Jan Jansen, forthcoming, "Central Bank Communication And Monetary Policy: A Survey Of Theory And Evidence" Journal of Economic Literature, forthcoming.

Brandt, Michael, John Cochrane, and Pedro Santa Clara, 2006, "International Risk Sharing is Better Than You Think, Or Exchange Rates are Too Smooth" Journal of Monetary Economics, Vol 53 (4), 671-698.

Chari, V V , Kehoe, Patrick J, and McGrattan, Ellen R, 2002. "Can Sticky Price Models Generate Volatile and Persistent Real Exchange Rates?," Review of Economic Studies, Blackwell Publishing, Vol. 69 (3), 533-63, July.

Calvo, Guillermo A, 1983 "Staggered prices in a utility-maximizing framework," Journal of Monetary Economics, Vol. 12 (3), 383-398

Devereux Michael B. and Charles Engel, 2002, "Exchange Rate Pass-Through, Exchange Rate Volatility, and Exchange Rate Disconnect," Journal of Monetary Economics, Vol. 49 (5), 913-940.

_ 2003, "Monetary Policy in the Open Economy Revisited: Price Setting and Exchange-Rate Flexibility," The Review of Economic Studies, Vol. 70 (October), 765-83.

—_ 2006, "Expectations and Exchange Rate Policy," NBER Working Paper No. 12213 (Cambridge, Massachusetts: National Bureau of Economic Research).

_ 2 2007, "Expectations, Monetary Policy, and the Misalignment of Traded Goods Prices," forthcoming in "NBER International Seminar on Macroeconomics 2007”(Cambridge, Massachusetts: National Bureau of Economic Research).

Engel, Charles, Nelson C. Mark and Kenneth D. West, 2007, "Exchange Rate Models Are Not as Bad as You Think," NBER Working Paper No. 13318 (Cambridge, Massachusetts: National Bureau of Economic Research).

Engel, Charles and Kenneth D. West, 2006, "Exchange Rates and Fundamentals," Journal of Political Economy, Vol. 113 (3), 485-517

Engel, Charles and Akito Matsumoto, 2008, "Portfolio Choice and Risk Sharing in a Monetary Open-Economy DSGE Model," mimeo University of Wisconsin. 
Groen, Jan J J and Akito Matsumoto, 2004, "Real exchange rate persistence and systematic monetary policy behaviour," Bank of England working papers 231, Bank of England.

Hau, Harald, and Hélène Rey, 2004, “Can Portfolio Rebalancing Explain the Dynamics of Equity Returns, Equity Flows, and Exchange Rates?” American Economic Review P\&P, Vol. 94 (May), 126-33.

__ 2006, "Exchange Rates, Equity Prices, and Capital Flows," Review of Financial Studies, Vol. $19,273-317$

Ireland, Peter N., 2003, “Endogenous money or sticky prices?” Journal of Monetary Economics, Vol 50, 1623-1648.

Meese, Richard A. and Kenneth Rogoff, 1983, "Empirical Exchange Rate Models of the Seventies: Do They Fit Out of Sample?," Journal of International Economics, Vol. 14, 3-24.

Monacelli, Tommaso, 2004, "Into the Mussa Puzzle: Monetary Policy Regimes and the Real Exchange Rate in a Small Open Economy," Journal of International Economics, Vol. 62, 191-217.

Obstfeld, Maurice, and Kenneth Rogoff, 2003, "Risk and Exchange Rates," in Elhanan Helpman and Efraim Sadka, editors, "Contemporary Economic Policy: Essays in Honor of Assaf Razin," Cambridge University Press, 2003

Rigobon, Roberto and Brian Sack , 2004, “The Impact of Monetary Policy on Asset Prices, " Journal of Monetary Economics, November, Vol. 51 (8), 1553-75, 2004

Rotemberg, Julio J. 1982, "Sticky Prices in the United States," Journal of Political Economy, Vol. 90 (6), 1187-1211

West, Kenneth D, 1988, “Dividend Innovations and Stock Price Volatility," Econometrica, Vol. 56 (1), 37-61

Woodford, Michael, 2008, “The Fed's 'Enhanced' Communication Strategy: Work in Progress," mimeo, Columibia University 